\title{
Metal-Metal Synergy in Well-Defined Surface Tantalum-Iridium Heterobimetallic Catalysts for H/D Exchange Reactions
}

\author{
Sébastien Lassalle, ${ }^{[a]}$ Ribal Jabbour, ${ }^{[b]}$ Pauline Schiltz, ${ }^{[a]}$ Pierrick Berruyer, ${ }^{[b]}$ Tanya K. Todo- \\ rova, ${ }^{[c]}$ Laurent Veyre, ${ }^{[a]}$ David Gajan, ${ }^{[b]}$ Anne Lesage, ${ }^{[b]}$ Chloé Thieuleux ${ }^{[a]}$ and Clément Camp*[a]
}

[a] Laboratory of Chemistry, Catalysis, Polymers and Processes, $\mathrm{C}_{2} \mathrm{P}_{2}$ UMR 5265, Université de Lyon, Institut de Chimie de Lyon, CNRS, Université Lyon 1, ESCPE Lyon, 43 Bd du 11 Novembre 1918, F-69616 Villeurbanne, France.

[b] Université de Lyon, Centre de RMN à Hauts Champs de Lyon CRMN, FRE 2034, Université de Lyon, CNRS, ENS Lyon, UCB Lyon 1, 69100 Villeurbanne, France.

[c] Laboratoire de Chimie des Processus Biologiques, UMR 8229 CNRS, Collège de France, Université Paris 6, 11 Place Marcelin Berthelot, 75231 Paris Cedex 05, France.

KEYWORDS Surface organometallic chemistry, early/late heterobimetallics, H/D exchange, catalysis, hydrides, tantalum, iridium.

\begin{abstract}
A novel heterobimetallic tantalum/iridium hydrido complex, $\left[\left\{\mathrm{Ta}_{(}\left(\mathrm{CH}_{2}{ }^{t} \mathrm{Bu}\right)_{3}\right\}\left\{\mathrm{IrH}_{2}\left(\mathrm{Cp}^{*}\right)\right\}\right] \mathbf{1}$, featuring a very short metal-metal bond, has been isolated through an original alkane elimination route from $\mathrm{Ta}\left(\mathrm{CH}^{t} \mathrm{Bu}\right)\left(\mathrm{CH}_{2}{ }^{t} \mathrm{Bu}\right)_{3}$ and $\mathrm{Cp}^{*} \mathrm{IrH}_{4}$. This molecular precursor has been used to synthesize well-defined silica-supported low-coordinate heterobimetallic hydrido species $\left[\equiv \mathrm{SiOTa}\left(\mathrm{CH}_{2}{ }^{t} \mathrm{Bu}\right)_{2}\left\{\mathrm{IrH}_{2}\left(\mathrm{Cp}^{*}\right)\right\}\right] 5$ and $\left[\equiv \mathrm{SiOTa}\left(\mathrm{CH}_{2}{ }^{t} \mathrm{Bu}\right) \mathrm{H}\left\{\mathrm{IrH}_{2}\left(\mathrm{Cp}^{*}\right)\right\}\right] \mathbf{6}$ using a surface organometallic chemistry approach (SOMC). The SOMC methodology prevents undesired dimerization as encountered in solution and leading to a tetranuclear species $\left[\left\{\mathrm{Ta}\left(\mathrm{CH}_{2}{ }^{t} \mathrm{Bu}\right)_{2}\right\}\left(\mathrm{Cp}^{*} \mathrm{IrH}\right)\right]_{2}, 4$. This approach therefore allows access to unique low-coordinate species not attainable in solution. These original supported $\mathrm{Ta} / \mathrm{Ir}$ species exhibit drastically enhanced catalytic performances in H/D exchange reactions with respect to (i) monometallic analogues as well as (ii) homogeneous systems. In particular, material 6 promotes the $\mathrm{H} / \mathrm{D}$ exchange between fluorobenzene and $\mathrm{C}_{6} \mathrm{D}_{6}$ or $\mathrm{D}_{2}$ as deuterium sources with excellent productivity (TON up to 1422; TOF up to $\left.23.3 \mathrm{~h}^{-1}\right)$ under mild conditions $\left(25^{\circ} \mathrm{C}\right.$, subatmospheric $\mathrm{D}_{2}$ pressure) without any additives.
\end{abstract}

\section{INTRODUCTION}

A current frontier in organometallic chemistry is the cooperative activity between two distinct metal centers to induce new reactivity pathways and foster original transformations not possible with monometallic species. ${ }^{1-3}$ In particular, molecular edifices associating early and late transition metals featuring a polar metal-metal interaction are particularly promising to promote the heterolytic cleavage of strong, unactivated apolar bonds $(\mathrm{H}-\mathrm{H}, \mathrm{C}-\mathrm{H}, \mathrm{N} \equiv \mathrm{N}$ etc.) and could open attractive opportunities for unprecedented reactivity in catalysis. ${ }^{4^{-6}}$ While a diverse array of molecular early/late organometallic species have been synthesized, their reactivity in catalysis is largely underexploited. Although we note a stimulating resurgence of interest for this field in the past few years, catalytic applications of early/late heterobinuclear metal complexes are still very limited to date. ${ }^{7-16}$ This can, in part, be explained by the common practice of using bulky polydentate bridging ligands in order to direct the assembly of the two metals and stabilize the resulting edifices but this also prevents substrates to bind across the two metals and thus limits the range of accessible metal-metal synergistic effects.
One possible strategy to overcome this limitation and access low-coordinate systems would be (i) to target early/late heterobimetallic systems with simple ligands, assembled through metal-metal bonds, in combination with (ii) a surface organometallic chemistry (SOMC) ${ }^{17}$ approach. Indeed, the anchoring of molecular complexes to the surface of a solid support through SOMC can afford low-coordinate organometallic species not accessible in solution and featuring unique molecular structures and reactivity, among which alkane metathesis and $\mathrm{N}_{2}$ splitting promoted by tantalum hydrides supported on silica are flagship examples..$^{1-20}$

To date, the vast majority of SOMC studies have however focused on monometallic species. ${ }^{17}$ Silica-supported $d$ block heterobimetallic species are remarkably rare and so far limited to a handful of early/early transition metals species (groups 4, 5 and 6) obtained through stepwise grafting of two independent monometallic molecular precursors. ${ }^{21-}$ ${ }^{25} \mathrm{Ni}$ (II) complexes were supported onto alkyl-aluminum functionalized silicas to generate olefin polymerization active catalysts. ${ }^{26-28}$ The thermal decomposition of heterometallic late metal clusters on metal oxide supports was also described. ${ }^{29,30}$ The lack of supported early/late heterobimetallic systems is - in part - due to the difficulty to access 
such edifices in a controlled manner, which requires smart, designated precursors and synthetic strategies to combine two metal centers with different chemical properties on a single solid support. Indeed, the methodologies classically employed for immobilizing both metal categories (early $v s$ late) are often orthogonal, which may explain why the synthesis of well-defined supported early/late heterobimetallic complexes have been so far unexplored. Oxophilic early transition metal derivatives (for eg. tantalum species) are usually grafted directly onto the surface of an oxide material (for eg. silica) via protonolysis of a metal- $\mathrm{X}$ bond $(\mathrm{X}=$ alkyl or halide) with surface hydroxyl groups (for eg. silanol $\equiv \mathrm{Si}-\mathrm{O}-\mathrm{H})$ and subsequent formation of a strong metal-O bond (for eg. siloxy $\equiv \mathrm{Si}-\mathrm{O}-$-metal) and release of $\mathrm{H}-\mathrm{X}$. In the case of late metals such as iridium or ruthenium, the metaloxygen bond is much weaker and can lead to uncomplete grafting, leaching or formation of undesired metal nanoparticles. ${ }^{31-33}$ To circumvent these issues, functionalized metal oxide supports are generally preferred. Tailored hybrid silica matrices containing regularly distributed N-heterocyclic carbenes have been developed in our group and used to access single-site heterogeneous catalysts based on $\mathrm{Ru}$ - or Ir-NHC units. ${ }^{33-36}$ Recently, the groups of Delferro and Conley also reported the use of acidic sulfated metal oxides to support iridium sites active in alkanes transformations $3^{37,38}$ and well-defined $\mathrm{Ni}$ and Pd catalysts for olefin polymerization. 39,40

Thus, the type of supports conventionally used for iridium and ruthenium on one hand and tantalum on the other hand are different, and as a result these metals cannot be easily combined using two independent monometallic precursors on a single support.

To address this issue, we report here a new modular synthetic approach exemplified on a heterobimetallic $\mathrm{Ta} / \mathrm{Ir}$ system. First, a robust molecular precursor featuring a $\mathrm{Ta}=\mathrm{Ir}$ double bond to ensure proximity between the two metals is formed. Then Ta chemistry is used to establish strong Ta-siloxide bonds with silicon oxide materials in order to anchor the Ta/Ir species at the silica surface, ultimately yielding well-defined early/late heterobimetallic supported catalysts. The atomic-scale structure of these original Ta/Ir complexes is characterized in detail and elucidated through a combination of techniques including high-resolution solid-state NMR spectroscopy and periodic DFT calculations. Furthermore, we demonstrate that these original supported $\mathrm{Ta} / \mathrm{Ir}$ species exhibit drastically enhanced catalytic performances in H/D exchange reactions with respect to the monometallic analogues as well as the corresponding homogeneous systems.

\section{RESULTS AND DISCUSSION}

\section{HETEROBIMETALLIC COMPLEXES IN SOLUTION}

Alkane elimination resulting from the reaction between a nucleophilic metal alkyl derivative and a Brønsted acidic metal hydride species is an efficient and clean - yet seldom used - synthetic methodology to access metal-metal bonds. ${ }^{41-43}$ This led us to investigate the reactivity of the tantalum tris-neopentyl neopentylidene complex
$\mathrm{Ta}\left(\mathrm{CH}^{t} \mathrm{Bu}\right)\left(\mathrm{CH}_{2}{ }^{t} \mathrm{Bu}\right)_{3}{ }^{44}$ towards the iridium tetrahydride complex $\mathrm{Cp}^{*} \mathrm{IrH}_{4}{ }^{45}$ The reaction is carried out in a 1:1 stoichiometric ratio in pentane at room temperature and affords quantitatively the heterobimetallic complex $\left[\left\{\mathrm{Ta}\left(\mathrm{CH}_{2}{ }^{t} \mathrm{Bu}\right)_{3}\right\}\left\{\mathrm{IrH}_{2}\left(\mathrm{Cp}^{*}\right)\right\}\right], \mathbf{1}$ with evolution of one equivalent of neopentane as quantified by NMR spectroscopy (Scheme 1).

Scheme 1. Alkane elimination synthesis of the Ta-Ir heterobimetallic species 1.

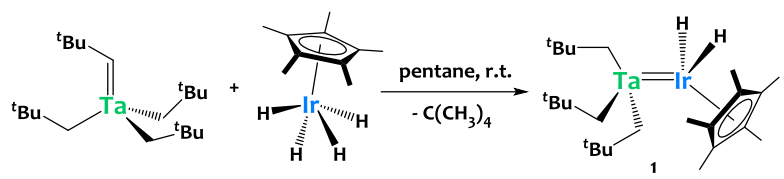

The identity of $\mathbf{1}$ was confirmed by infrared (IR) and multi-nuclei $\left({ }^{1} \mathrm{H},{ }^{13} \mathrm{C}\right)$ solution NMR spectroscopies, elemental analysis and X-ray diffraction studies. In the ${ }^{1} \mathrm{H}$ NMR spectrum (recorded in a toluene- $d_{8}$ solution) the hydride resonance appears as a high-field singlet at $\delta=-12.0$ $\mathrm{ppm}$. At the lowest temperature reached $(228 \mathrm{~K})$, the spinlattice relaxation time $\left(T_{1}\right)$ measured for the hydride protons in $\mathbf{1}$ is $677 \mathrm{~ms}$, and the minimum spin-lattice relaxation time $T_{1 \min }$ is estimated to be $430 \mathrm{~ms}$ for a temperature of $203 \mathrm{~K}$, which is in agreement with a classical iridium dihydride (versus a dihydrogen complex). ${ }^{46,47}$ The IR spectrum of 1 exhibits a M-H stretching vibration signal at $2056 \mathrm{~cm}^{-1}$ which supports a terminal iridium hydride description. For comparison, the terminal Ir-H stretching frequency of $\mathrm{Cp}^{*} \mathrm{IrH}_{4}$ is $2150 \mathrm{~cm}^{-145}$ and that of $\mathrm{Cp}^{*} \operatorname{Ir}(\mathrm{CO}) \mathrm{H}_{2}$ and $\mathrm{Cp}^{*} \operatorname{Ir}\left(\mathrm{PMe}_{3}\right)\left(\mathrm{CH}_{3}\right) \mathrm{H}$ are 2131 and $2090 \mathrm{~cm}^{-1}$ respectively ${ }^{48-50}$ while the absorption due to bridging hydride ligands typically occurs at lower wavenumbers, for instance at $936 \mathrm{~cm}^{-1}$ in $\left\{\left[C \mathrm{Cp}^{*} \mathrm{Ir}\right]_{2}(\mu-\mathrm{H})_{3}\right\}\left\{\mathrm{PF}_{6}\right\} .^{5^{1}}$

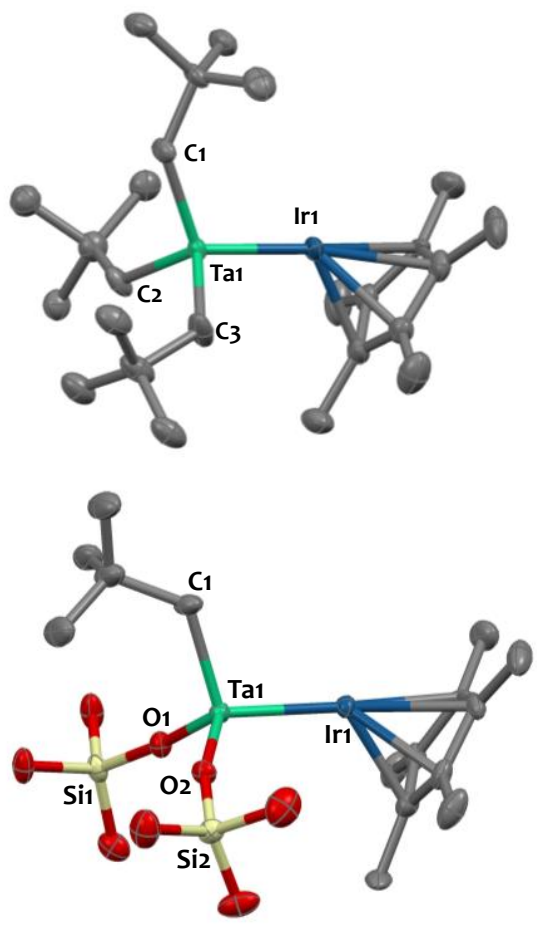




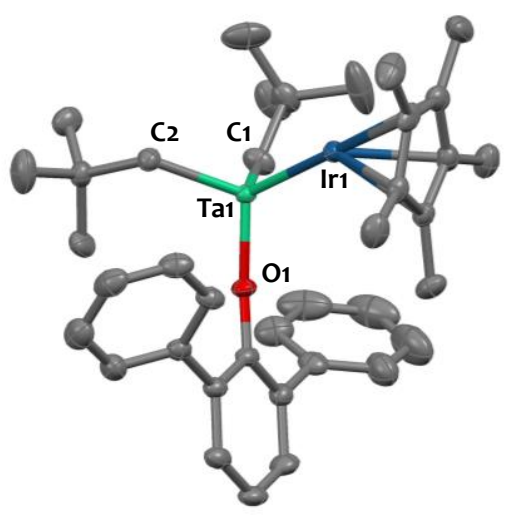

Figure 1. Solid-state molecular structures of 1 (top), 2 (middle) and 3 (bottom). Ellipsoids are represented with ${ }_{50} \%$ probability. ${ }^{t} \mathrm{Bu}$ groups from the $\mathrm{OSi}\left(\mathrm{O}^{t} \mathrm{Bu}\right)_{3}$ ligands and hydrogen atoms have been omitted for clarity. The asymmetric unit of 3 comprises of two crystallographic independent molecules of which only one is shown. Selected bond distances $(\AA)$ and angles $\left(^{\circ}\right)$ for 1: Ta1-Ir1 2.3559(6), Ta1-C1 2.113(12), Ta1-C2 2.126(12), Ta1-C3 2.134(12), Ir1-C $\mathbf{p}^{*}$ centroid 1.936(1), Ta1-Ir1-C $\mathbf{p}^{*}$ centroid 151.3; for 2: Ta1-Ir1 2.3992(6), Ta1-O1 1.881(8), Ta1-O2 1.886(7), Ta1-C1 2.159(12), Ir1-C p $^{*}$ centroid $1.937(1)$, Ta1-Ir1-C ${ }^{*}{ }_{\text {centroid }} 154.4$; for 3 : Ta1-Ir1 2.386(6), Ta1-O1 1.871(2), Ta1-C1 2.136(6), Ta1-C2 2.168(4),

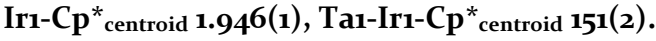

Single crystals suitable for X-ray diffraction were grown upon sublimation of compound $1\left(40^{\circ} \mathrm{C}\right.$ under $\left.10^{-5} \mathrm{mBar}\right)$. The most salient feature of the solid-state structure of $\mathbf{1}$, shown on Figure 1, is the metal-metal bond. Of the handful known complexes featuring a tantalum iridium/rhodium

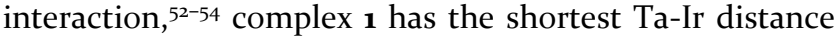
(2.3559(6) A) reported to date, which is $0.25 \AA$ less than the sum of the respective metallic radii (Ta: $1.343 \AA$; Ir: $1.260 \AA$; sum $=2.603 \AA) .55$ The formal shortness ratio $(\mathrm{r}=0.905)^{56}$ is below unity which is indicative of a multiple metal-metal bond order, as confirmed by our orbital analysis (see below). The Ta center is nearly tetrahedral $\left(\mathrm{C}_{\mathrm{Np}}-\mathrm{Ta}-\mathrm{C}_{\mathrm{Np}}\right.$ angles from $107.5(5)^{\circ}$ to $108.6(6)^{\circ}$; $\mathrm{Ir}-\mathrm{Ta}-\mathrm{C}_{\mathrm{Np}}$ angles from $104.3(4)^{\circ}$ to $115.1(3)^{\circ}$ ) and the Ta- $C_{\mathrm{Np}}$ bond lengths (average value 2.21(1) $\AA$ ) are as expected for neopentyl groups. ${ }^{57,58}$ Even if the hydrides could not be located in the XRD Fourier Map, hint of their presence is given by the marked tilting of the $C \mathrm{p}^{*}$ ligand with respect to the Ta-Ir bond $\left(\mathrm{Cp}^{*}{ }_{\text {cen- }}\right.$ troid-Ir-Ta angle of $151.3^{\circ}$ ), as a result of the three-legged piano-stool coordination geometry around the Ir center, which is archetypal of Cp* Ir complexes.

Quantum chemical calculations using density functional theory (DFT), followed by the complete active space selfconsistent field (CASSCF) method were performed on $\mathbf{1}$ to get deeper insights into its molecular and electronic structure (see SI for computational details). The geometry of complex 1 optimized in benzene at the PBEo/def2-TZVP level of theory with the SMD implicit solvation model is in excellent agreement with the experimental X-ray single crystal structure: the Ta-Ir bond distance of $2.366 \AA$, is within $0.01 \AA$ of the corresponding value in the crystal structure, and the Ta-Ir-C $\mathrm{C}^{*}$ centroid angle of $150.2^{\circ}$ is within $1^{\circ}$. The structure contains two terminal $\mathrm{I}-\mathrm{H}$ hydrides with bond distances of 1.615 and $1.618 \AA$, giving rise to two $\mathrm{Ir}-\mathrm{H}$ vibrations computed at 2148 and $2186 \mathrm{~cm}^{-1}$ and associated with the in-phase and out-of-phase stretching modes, in good agreement with the experimental value of $2056 \mathrm{~cm}^{-1}$. The Ta-Ir metal-metal bonding was quantified in terms of effective bond order (EBO), defined as $\left(\eta_{b}-\eta_{a}\right) /\left(\eta_{b}+\eta_{a}\right)$, where $\eta_{\mathrm{b}}$ is the occupation number for the bonding natural orbital, $\eta_{\mathrm{a}}$ is the occupation number for the corresponding antibonding natural orbital. The molecular orbitals forming the active space of $\mathbf{1}$, along with their corresponding occupation numbers are given in Figure S28. The EBO analysis shows the $\sigma$ and $\pi$ effective bond orders of 0.93 and 0.94 respectively, thus indicating the same strength of the two bonds. As a result, the total bond order for complex $\mathbf{1}$ is 1.87, suggesting a double Ta-Ir metal-metal bond.

Scheme 2. Protonolysis reactivity of 1.
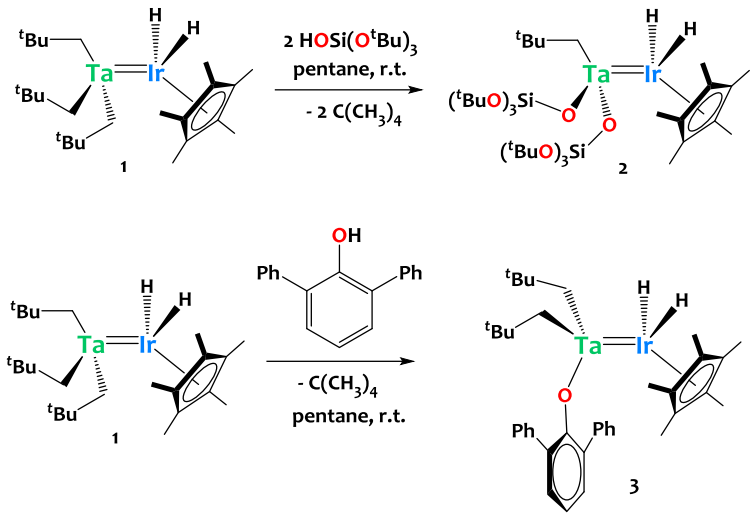

In order to anticipate the reactivity of $\mathbf{1}$ with surface silanol groups and to provide a structural model of the immobilized species, we investigated the stoichiometric reaction of 1 with molecular silanols and phenols. Metal derivatives of the bulky tris(tert-butoxy)siloxide ligand can, in a first approach, be considered as models for silica-supported organometallic catalysts. ${ }^{59^{-6}}$ Treatment of 1 with 2 equivalents of $\mathrm{HOSi}\left(\mathrm{O}^{t} \mathrm{Bu}\right)_{3}$ leads to the clean formation of $\left[\left\{\mathrm{Ta}\left(\mathrm{OSi}\left(\mathrm{O}^{t} \mathrm{Bu}\right)_{3}\right)_{2}\left(\mathrm{CH}_{2}{ }^{t} \mathrm{Bu}\right)\right\}\left\{\mathrm{IrH}_{2}\left(\mathrm{Cp}^{*}\right)\right\}\right]$ 2, resulting from the protonolysis of two Ta-neopentyl bonds (Scheme 2). Surprisingly, when the same reaction is performed with only 1 equiv. $\mathrm{HOSi}\left(\mathrm{O}^{t} \mathrm{Bu}\right)_{3}$, a $1: 1$ mixture of 1 and 2 is obtained and no evidence of the mono-substituted product is found. Complex 2 was fully characterized by elemental analysis, multi-nuclei liquid state NMR and IR spectroscopies. Its solid-state structure, shown on Figure 1, was determined by single-crystal X-ray diffraction. The spectroscopic and structural features of $\mathbf{2}$ are for most part unaffected by the substitution of two alkyls by two siloxides. From this experiment we can draw three main conclusions: (i) the Ta-Np bond in $\mathbf{1}$ is preferentially cleaved by the $\mathrm{Si}$ $\mathrm{OH}$ groups, (ii) the iridium coordination sphere remains nearly identical and (iii) the mono-substituted species is not stable in solution.

In order to better mimic the first coordination sphere of the immobilized surface species, which is monopodal (see below), we tried to isolate a molecular species having only one oxygen and two remaining alkyls bound at Ta. We thus turned our attention to the reactivity of $\mathbf{1}$ towards phenol 
derivatives featuring various steric profiles, which was found to be key in this protonolysis reactivity. 2,6-Di-tertbutyl-p-cresol does not react with $\mathbf{1}$, even after prolonged heating (up to $110^{\circ} \mathrm{C}$ ), most likely due to the large steric hindrance imparted by the ${ }^{t} \mathrm{Bu}$ groups. In contrast, when 1 is treated with 1 equivalent of 2,6-Di-methylphenol a mixture of mono-, di- and tri-substituted species is obtained, along with unreacted $\mathbf{1}$. In that case, the steric profile of the phenol derivative is probably too low to avoid polysubstitution. Gratifyingly, the reaction of 1 with 1 equivalent of 2,6-Diphenylphenol cleanly provides the desired species $\left[\left\{\mathrm{Ta}(\mathrm{OAr})\left(\mathrm{CH}_{2}{ }^{t} \mathrm{Bu}\right)_{2}\right\}\left\{\mathrm{IrH}_{2}\left(\mathrm{Cp}^{*}\right)\right\}\right] \quad 3\left(\mathrm{OAr}=2,6-(\mathrm{Ph})_{2^{-}}\right.$ $\mathrm{C}_{6} \mathrm{H}_{3} \mathrm{O}$ ), which was isolated in $96 \%$ yield (Scheme 2 ). The ${ }^{1} \mathrm{H}$ NMR spectrum for 3 is in agreement with the proposed formula, with the hydride resonance integrating for $2 \mathrm{H}$ found at $\delta=-11.3 \mathrm{ppm}$. The introduction of the aryloxy ligand induces some rigidity and loss of symmetry, as reflected by the ${ }^{1} \mathrm{H}$ resonances for the tantalum-bound methylene groups from the two neopentyl ligands $\left(\mathrm{Ta}-\mathrm{CH}_{2}\right)$ appearing as two diastereotopic doublets integrating for $2 \mathrm{H}$ each, with distinct chemical shifts and strong ${ }^{2} J_{\mathrm{HH}}$ couplings ( 0.08 and -0.11 ppm, ${ }^{2} J_{\mathrm{HH}}=14.4 \mathrm{~Hz}$ ). The IR spectrum for 3 displays two bands attributed to Ir-H stretches (inphase and out-of-phase modes) at 2094 and $2054 \mathrm{~cm}^{-1}$, (see Figure S24) which is similar to what was found for the supported species (see Figure 2). The solid-state structure of 3 is shown in Figure 1-bottom. The metrical parameters of 3 are for most part similar to those in 1, with the exception of the $\mathrm{Ta}=\mathrm{Ir}$ bond which is slightly elongated from 2.3559(6) $\AA$ in 1 to 2.386(6) $\AA$ in 3. Overall the geometries and coordination environments of both metals in 1, 2 and 3 are very similar.

Dihydrogen treatment of $1\left(1 \mathrm{bar}, 80^{\circ} \mathrm{C}\right)$ affords the tetranuclear complex $\left[\left\{\mathrm{Ta}\left(\mathrm{CH}_{2}{ }^{t} \mathrm{Bu}\right)_{2}\right\}\left(\mathrm{Cp}^{*} \mathrm{IrH}\right)\right]_{2}, 4$ (Scheme 4$) \cdot 4$ formally results from reductive elimination of 1 equivalent of neopentane per Ta center (corroborated by ${ }^{1} \mathrm{H}$ NMR analysis) from the heterobimetallic precursor $\mathbf{1}$ followed by dimerization. The resonance of the hydride ligand in $\mathbf{4}$ is observed at $\delta=-10.6 \mathrm{ppm}$ by ${ }^{1} \mathrm{H}$ NMR. Integration of the ${ }^{1} \mathrm{H}$ NMR signals shows a $1: 1 \mathrm{Cp}^{*}$ :hydride ratio, which is in agreement with a iridium monohydride formula. The IR spectrum for 4 displays a sharp signal at $2090 \mathrm{~cm}^{-1}$ which is characteristic of a terminal iridium-hydride stretch.

Scheme 4. Formation of the tetranuclear species 5 upon $\mathrm{H}_{2}$ treatment of 1 .

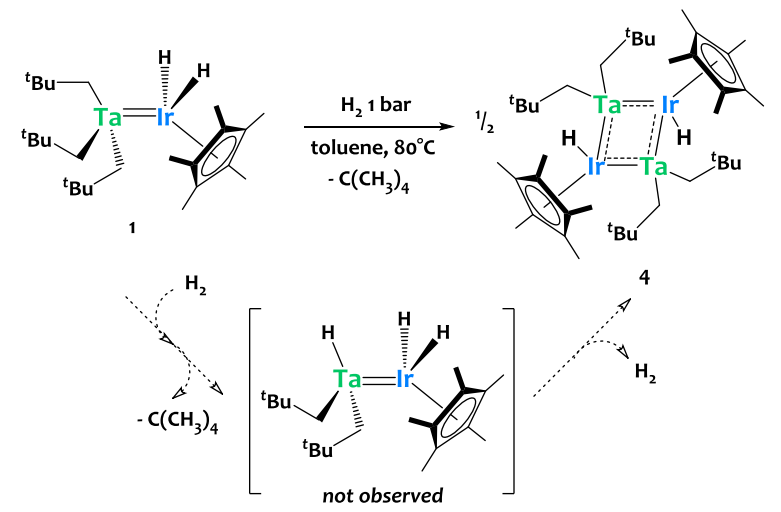

Definite evidence for the structure of 4 was obtained by single-crystal XRD. In the solid-state, complex 4 exists as a tetramer forming a $\mathrm{Ta}_{2} \mathrm{Ir}_{2}$ planar core featuring an inversion point at the center of the heterometallacycle core (Figure 4 ). The $\mathrm{Ta}_{2} \mathrm{Ir}_{2}$ core adopts a diamond geometry with $\mathrm{o}^{\circ}$ Ta-Ir-Ta-Ir torsion angles, Ta1-Irı-Taı\# and Ir1-Ta1-Irı\# angles of $76.07(1)^{\circ}$ and $103.93(1)^{\circ}$, respectively. The Ta-Ir bonds (2.4443(3) $\AA$ and 2.4575(4) $\AA$ ) are very short (although slightly longer than in 1 and 2) and the formal shortness ratio $(r=0.94)$ is below unity which denotes multiple metal-metal bonding in this compound. As in $\mathbf{1}$, the $\mathrm{Cp}^{*}$ ligand is tilted with regard to the Ta-Ir bond and the Ta$\mathrm{Ir}-\mathrm{CP}^{*}$ centroid angle is $136.69(1)^{\circ}$. The terminal hydride ligand was located in the Fourier difference map close to iridium and slightly points towards the core of the molecule as a result of the iridium three-legged piano-stool coordination geometry. The XRD data thus confirms the terminal coordination mode of the hydrido ligand in $\mathbf{4}$, in agreement with IR spectroscopic measurements. The tantalum alkyl bonds are as expected, $5^{8}$ and the Ta centers adopt a pseudo-tetrahedral geometry.

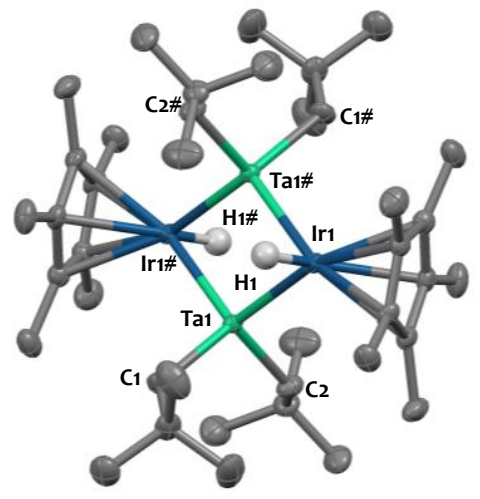

Figure 4. Solid-state molecular structure of 4. Ellipsoids are represented with $50 \%$ probability. Hydrogen atoms (except Ir hydrides) have been omitted for clarity. Selected bond distances $(\AA)$ and angles $\left(^{\circ}\right)$ : Ta1-Ir1 2.4443(3),

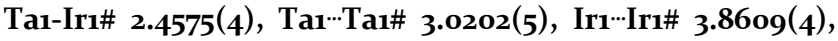
Ta1-C1 2.140(7), Ta1-C2 2.164(7), Ir1-C p $^{*}$ centroid 2.o21, Ta1-Ir1Ta1\# 76.07(1), Ir1-Ta1-Irı\# 103.93(1), Ta1-Ir1-C ${ }^{*}{ }_{\text {centroid }}$ 136.69(1).

The DFT optimized structure of complex 4 (Figure S30) is in excellent agreement with the XRD structure. The two Ta-Ir distances are equal to $2.465 \AA$ and the Ta-Ir-Cp* ${ }^{*}$ centroid angle is $137 \cdot 3^{\circ}$. The two $\mathrm{Ir}-\mathrm{H}$ bonds have bond lengths of $1.614 \AA$, which are virtually the same as the $\mathrm{Ir}-\mathrm{H}$ distances in complex $\mathbf{1}$, and are associated with a single vibrational frequency computed at $2180 \mathrm{~cm}^{-1}$.

As noted above, the structure of 4 can be viewed as resulting from reductive elimination of neopentane from $\mathbf{1}$, followed by dimerization of the putative low-coordinate intermediate. At first glance, it is striking that dihydrogen, which is not consumed in the reaction balance, promotes reductive elimination and leads to a species containing less hydrides. A possible pathway to account for the formation of 4 begins with the sigma-bond metathesis of a Ta-Np group resulting in a tris-hydride species (Scheme 4), which 
then reductively-eliminates $\mathrm{H}_{2}$ in a bimolecular process leading to dimerization. Such hypothesis is supported by the reactivity of the surface-organometallic analogous species (see below).

The tetranuclear cluster $\mathbf{4}$ is thermally stable, even in the presence of $\mathrm{H}_{2}$, and does not undergo sigma-bond metathesis of the remaining Ta-Np groups nor dissociation to a dinuclear species, at least up to $110^{\circ} \mathrm{C}$ under 800 mbar of $\mathrm{H}_{2}$ for $24 \mathrm{~h}$. Surprisingly, 2 does not react upon exposure to $\mathrm{H}_{2}$, even after prolonged heating $\left(24 \mathrm{~h}, 110^{\circ} \mathrm{C}\right)$. Although we do not have a clear explanation, hydrogenolysis of a tantalumneopentyl bond in $\mathbf{1}$ therefore appears much easier than in 2 or 4. Unfortunately, complex 3 does not react with $\mathrm{H}_{2}$ at room temperature, and is unstable upon gentle heating $\left(50^{\circ} \mathrm{C}\right)$ under argon or $\mathrm{H}_{2}$ atmospheres to yield intractable mixture of species.

\section{SURFACE ORGANOMETALLIC CHEMISTRY}

The SBA-15 silica support was dehydroxylated under high-vacuum $\left(10^{-6} \mathrm{mBar}\right)$ at $700^{\circ} \mathrm{C}$, yielding a material (namely SBA-15700) featuring a low density of surface hydroxyl groups (ca. $0,54=\mathrm{Si}-\mathrm{OH}$ groups per $\mathrm{nm}^{2}$ ), required for ensuring sites-isolation. This SBA-15700 material still contains high loadings of reactive surface silanols per gram (c.a. $4.86 \times 10^{20}$ sites. $\mathrm{g}^{-1}$ ) due to the high surface area of this mesoporous silica $\left(895 \mathrm{~m}^{2} \cdot \mathrm{g}^{-1}\right.$, see SI). The high loading of surface $\equiv \mathrm{Si}-\mathrm{OH}$ groups is essential for an in-depth characterization of the grafted organometallic species by advanced ${ }^{13} \mathrm{C}$ and ${ }^{~} \mathrm{H}$ Magic Angle Spinning (MAS) solid-state NMR techniques (see below).

Scheme 3. Preparation of the silica-supported heterobimetallic species 5 .

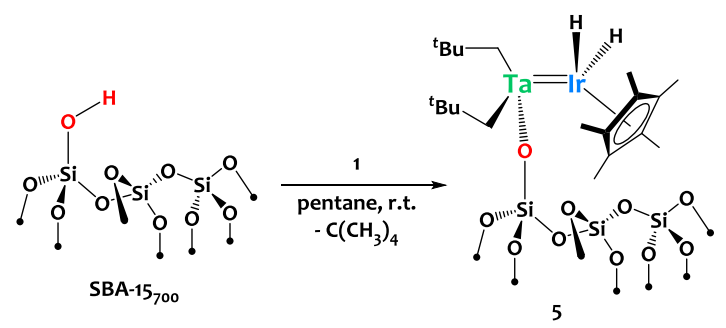

Upon treatment of SBA-15700 with a pentane solution of 1 at r.t., the characteristic sharp IR band at $3747 \mathrm{~cm}^{-1}$ corresponding to isolated surface silanols disappears while new signals attributed to $v(\mathrm{C}-\mathrm{H})$ stretches of the neopentyl and $\mathrm{Cp}^{*}$ ligands at $2960-2860 \mathrm{~cm}^{-1}$ and signals assigned to $v(\mathrm{Ir}-$ $\mathrm{H})$ stretches at 2064 and $2037 \mathrm{~cm}^{-1}$ appear (Figure 2). 1 equiv. of neopentane is evolved per grafted $\mathrm{Ta}$, as quantified by GC. These analyses are consistent with the chemical grafting of the precursor onto silica via protonolysis of one Ta-Np group by a surface silanol, yielding a monopodal $\left[\equiv \mathrm{SiOTa}\left(\mathrm{CH}_{2}{ }^{t} \mathrm{Bu}\right)_{2}\left\{\operatorname{IrH}_{2}\left(\mathrm{Cp}^{*}\right)\right\}\right]$ species $\mathbf{5}$. Unlike what seen in solution during the synthesis of 2 , it is important to note that the formation of a bipodal species is not possible on SBA- $15_{70}$ which features merely isolated $\mathrm{Si}-\mathrm{OH}$ groups. The Ta loading (9.3 wt \%) corresponds to o.54 Ta sites per $\mathrm{nm}^{2}$ of silica. This is in agreement with the titrated amount of surface silanol groups for SBA-1570o, and indicates full consumption of the surface silanol groups as also confirmed by the disappearance of the $v(\mathrm{OH})$ stretching band by IR (Figure 2). The elemental analysis (Expected: \%C 12.6, \%H 2.1, \%Ta 9.5, \%Ir 10.1 Found: \%C 12.6, \%H 2.0, \%Ta 9.3, \%Ir 10.1) is in excellent agreement with the proposed formula for 3 .

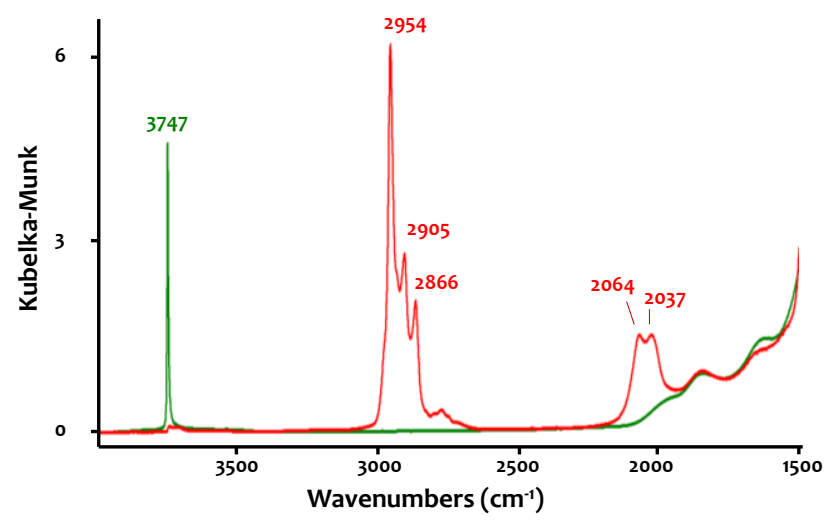

Figure 2. Diffuse reflection infrared Fourier transform spectra of SBA-157oo (green line) and compound 5 (red line) recorded on powder materials under argon.

The ${ }^{1} \mathrm{H}$ solid-state NMR spectrum of 5 (Figure $3 \mathrm{~b}, 1 \mathrm{D}$ trace above the $2 \mathrm{D}$ spectrum) shows two main intense signals at 2.2 and $0.9 \mathrm{ppm}$ assigned to the $\mathrm{CH}_{3}$ groups of the $\mathrm{Cp}^{*}$ and $\mathrm{Np}$ moieties respectively, along with a broad signal at $-11.5 \mathrm{ppm}$ corresponding to the iridium hydrides, by analogy with the molecular precursor $\mathbf{1}$. The peak at $\mathbf{2 . 2}$ ppm also includes the resonance of the $\mathrm{CH}_{2}$ protons of the Np moiety. The ${ }^{13} \mathrm{C}$ CP-MAS NMR spectrum of 5 (Figure 3a) displays four resonances at 107.5, 93.9, 33.5 and $9.1 \mathrm{ppm}$, assigned to the $\mathrm{CH}_{2}(\mathrm{~Np}), \mathrm{C}\left(\mathrm{Cp}^{*}\right), \mathrm{CH}_{3}(\mathrm{~Np})$, and $\mathrm{CH}_{3}\left(\mathrm{Cp}^{*}\right)$ carbons respectively, in agreement with the proposed structure.

Two-dimensional (2D) proton double-quantum (DQ) and triple-quantum (TQ) NMR spectroscopy techniques were used to confirm the bis-hydride nature of the iridium site of $1 .{ }^{66}$ The DQ and TQ experiments yield $2 \mathrm{D}$ spectra with $\left(\omega_{1}, \omega_{2}\right)$ correlations between respectively pairs and triplets of dipolar coupled (i.e., spatially close) protons. The DQ frequency in the indirect $\omega_{1}$ dimension corresponds to the sum of the two single-quantum (SQ) frequencies of the two coupled protons and correlates in the $\omega_{2}$ dimension with the two individual proton resonances, while the TQ frequency in the $\omega_{1}$ dimension corresponds to the sum of the three $\mathrm{SQ}$ frequencies of the three coupled protons and correlates with the three individual proton resonances. Thus, the observation of a DQ or TQ peak implies a close proximity between the two or the three protons in question. In particular, two or three equivalent protons (or two or three protons having the same chemical shifts) will give rise to an autocorrelation peak located along the $\omega_{1}=2 \omega_{2}$ or the $\omega_{1}=3 \omega_{2}$ line of the $2 \mathrm{D}$ spectrum. Two-dimensional DQ and TQ correlation experiments can thus be applied to unambiguously determine the number of hydride protons attached to the metal centers. Proton multiple-quantum NMR spectroscopy was previously applied to successfully distinguish zirconium monohydride 
and bishydride surface species $^{67}$ or to identify methyl groups in surface tantalum complexes. ${ }^{68}$ The DQ spectrum of Figure $3 b$ shows an autocorrelation along the $\omega_{1}=2 \omega_{2}$ line at around $\left(\omega_{1}, \omega_{2}\right)=(-11.5 \mathrm{ppm},-23 \mathrm{ppm})$ confirming the presence of two hydride protons. Conversely, the TQ correlation spectrum (Figure $\mathrm{S}_{17}$ ) does not display any autocorrelation for the hydride resonance along the $\omega_{1}=3 \omega_{2}$ line, as expected for a set of two isolated coupled protons. The DQ-SQ and TQ-SQ correlation spectra have in addition the expected auto-correlations for the $\mathrm{CH}_{3}$ groups of the $\mathrm{Cp}^{*}$ and $\mathrm{Np}$ moieties, as well as the expected off-diagonal correlations with the hydride protons (see SI for a detailed interpretation).
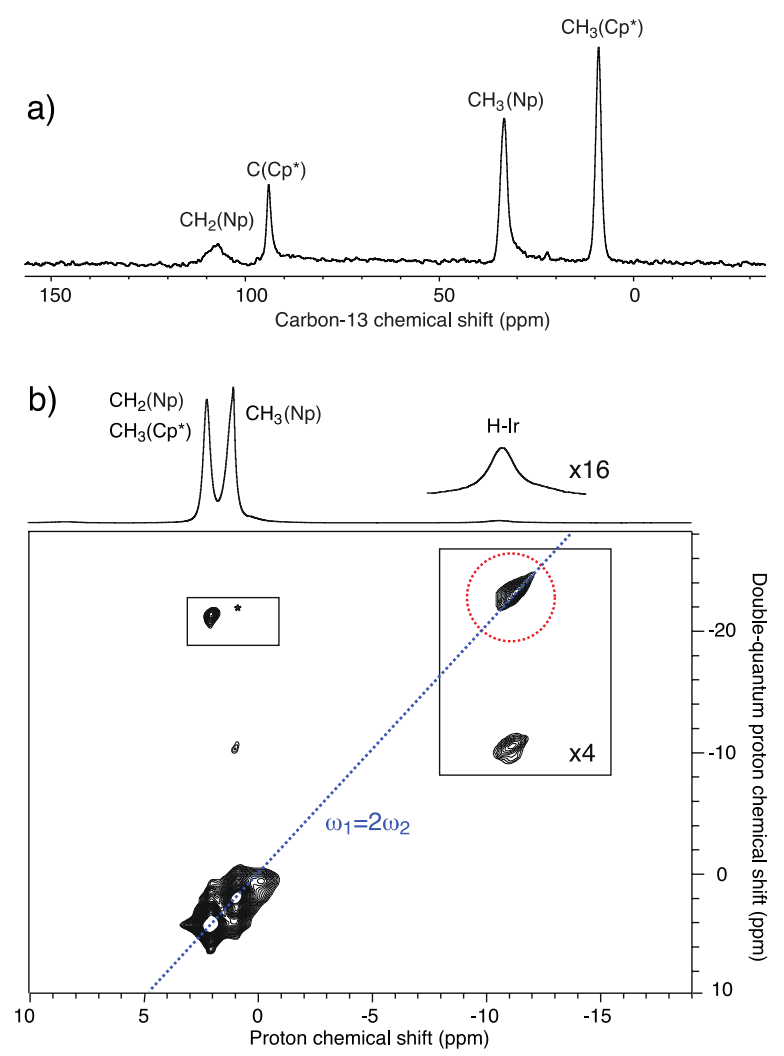

Figure 3. Solid-state NMR characterization of 5: (a) ${ }^{13} \mathrm{C}$ NMR CPMAS spectrum (125 MHz, $4 \mathrm{~mm}$ probe, $10 \mathrm{kHz}$ MAS frequency). (b) Proton SQ-DQ NMR spectrum (7oo MHz, $2.5 \mathrm{~mm}$ probe, $18 \mathrm{kHz}$ MAS frequency). The trace above the $2 \mathrm{D}$ plot corresponds to the one-dimensional ' $\mathrm{H}$-NMR spectrum. The dotted blue line is the $\omega_{1}=2 \omega_{2} \mathrm{di}-$ agonal. The dotted red circle underlines the autocorrelation of the hydride resonance. The spectrum has been zoomed by a factor 4 in the hydride region to clearly show the corresponding correlations: the auto-correlation at around (-11.5 ppm, -23 ppm) and the correlation between the hydrides and the neopentyl $\mathrm{CH}_{3}$ protons at around (-11.5 ppm, -10.5 ppm). The experimental conditions are described in detail in the experimental section. The SQ-TQ correlation spectrum of 5 is shown in Figure S17.

As stated previously, one great advantage of the SOMC approach is the possibility to access organometallic species with unprecedented molecular structures that cannot be accessed in solution, for e.g. low-coordinate metal species featuring unique reactivity.${ }^{17}$ In the present case, we postulated that the anchoring of $\mathbf{1}$ at the surface of silica would prevent the unwanted dimerization seen in solution leading to 4, and afford unique heterobimetallic hydrido species not reachable otherwise. Accordingly, we explored the reactivity of 5 towards $\mathrm{H}_{2}$.

Scheme 5. Preparation of material 6 from 5 .

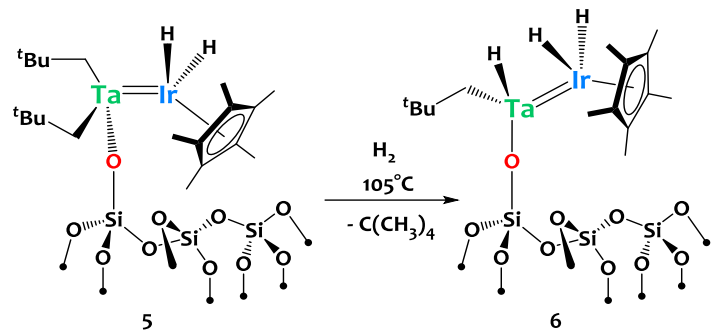

Under dihydrogen atmosphere (80o mbar, $\left.105^{\circ} \mathrm{C}, 10 \mathrm{~h}\right)$, the silica-supported species $\mathbf{5}$ is converted into $\left[\equiv \operatorname{SiOTa}\left(\mathrm{CH}_{2}{ }^{t} \mathrm{Bu}\right) \mathrm{H}\left\{\mathrm{IrH}_{2}\left(\mathrm{Cp}^{*}\right)\right\}\right], \mathbf{6}$ (Scheme 5 ) with release of 1 equiv. of neopentane per surface Ta, as titrated by GC. Here again, as for $\mathbf{1}$, only $\mathbf{1}$ neopentyl ligand undergoes hydrogenolysis at this temperature. IR monitoring of the solid shows a decrease in intensity of the $v(\mathrm{C}-\mathrm{H})$ stretches, in agreement with the evolution of neopentane, and the appearance of new bands around $1800 \mathrm{~cm}^{-1}$ (Figure 5). This signal, which disappears upon $\mathrm{H}_{2}-\mathrm{D}_{2}$ exchange and is restored upon re-exposure to $\mathrm{H}_{2}$ (see Figure $\mathrm{S}_{27}$ ), is attributed to a $v(\mathrm{Ta}-\mathrm{H})$ vibration mode issuing from a tantalum hydride species. For comparison, the previously reported silica-supported tantalum hydride species, $\left[(\equiv \mathrm{SiO})_{2} \mathrm{TaH}_{\mathrm{x}}\right]$, shows a characteristic IR band in the 1800 $\mathrm{cm}^{-1}$ region. ${ }^{69}$ Importantly, we do not detect $v(\mathrm{Si}-\mathrm{H})$ stretches (expected around $2200-2300 \mathrm{~cm}^{-1}$ ) which might arise from opening of the neighboring siloxane bridges and hydrogen transfer to the surface silicon atoms. This phenomenon is well-documented for monometallic early transition metal hydrides species supported on silica, ${ }^{67,70}$ but does not occur in the present system under this set of experimental conditions.

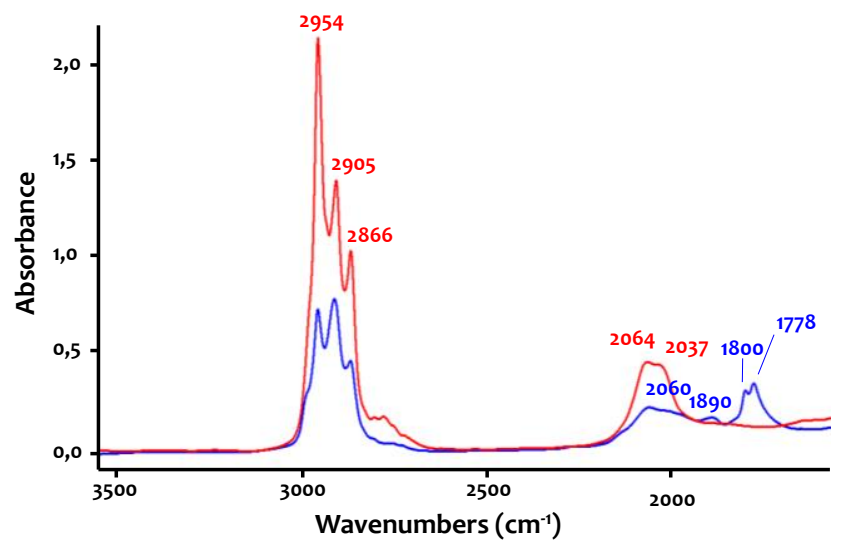

Figure 5. Infrared spectra of 5 (red line) and 6 (blue line) recorded in transmission on pelleted materials under argon. The SBA-157oo signal has been substracted to remove contribution from the support. 
The ${ }^{1} \mathrm{H}$ solid-state NMR spectrum of 6 (Figure $6 \mathrm{~b}, 1 \mathrm{D}$ trace above the $2 \mathrm{D}$ spectrum) is very similar to the one of 5. It displays two intense signals at 2.2 and $0.9 \mathrm{ppm}$ assigned as previously to the $\mathrm{CH}_{3}\left(\mathrm{Cp}^{*}\right)$ and $\mathrm{CH}_{2}(\mathrm{~Np})$, and to the $\mathrm{CH}_{3}(\mathrm{~Np})$ moieties respectively. We note that their intensity ratio is different, because the hydrogenation reaction leads to the release of some of the neopentyl ligands. The hydride signal appears as a broad resonance ranging from -10 to $-15 \mathrm{ppm}$. The ${ }^{13} \mathrm{C}$ CP MAS NMR spectrum of 6 (Figure 6a) displays four resonances at 106.9, 93.9, 33.3 and $8.9 \mathrm{ppm}$, assigned to the $\mathrm{CH}_{2}(\mathrm{~Np}), \mathrm{C}\left(\mathrm{Cp}^{*}\right), \mathrm{CH}_{3}(\mathrm{~Np})$, and $\mathrm{CH}_{3}\left(\mathrm{Cp}^{*}\right)$ carbons respectively, which agrees with the proposed structure. The proton DQ and TQ spectra (Figures S2o and 7b) of 6 show elongated autocorrelations along respectively the $\omega_{1}=2 \omega_{2}$ and $\omega_{1}=3 \omega_{2}$ diagonals, indicating the presence of three dipolar-coupled hydride protons. Additional auto- and off-diagonal correlations with the aliphatic resonances are observed (see Figure S21 for detailed assignements). Thus, the proposed structure for $\mathbf{6}$ is confirmed by proton multiple-quantum NMR experiments. The elongated shapes of the auto-correlations observed for the hydride resonances in both $\mathrm{DQ}$ and TQ correlation spectra reflect the inhomogeneous nature of the line broadening due to slight structural heterogeneity (likely originating from the support), as well as the presence of correlated chemical shift distributions. ${ }^{71,72}$ We note that fast exchange on the NMR time scale between Ta-H/Ir-H hydrides is very likely to occur, which would lead to the observation of a distribution of average chemical shifts.
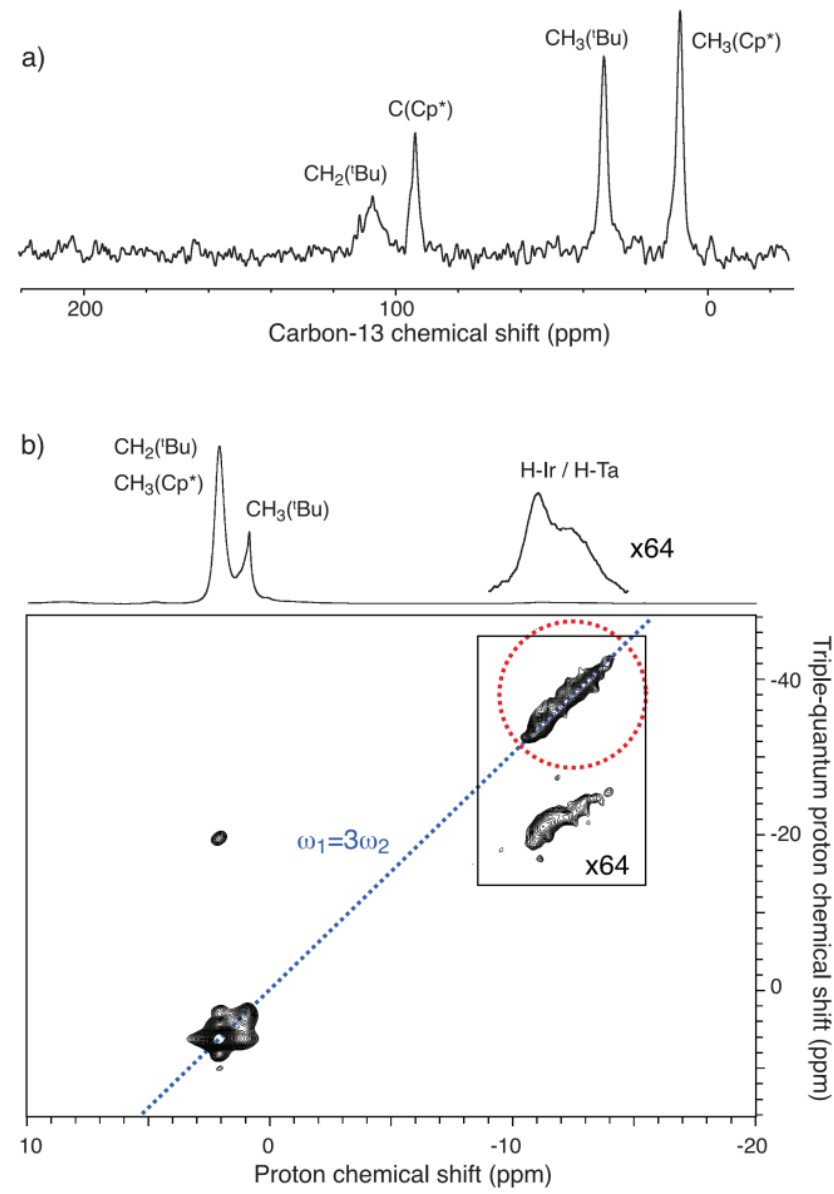

Figure 6. Solid-state NMR characterization of 6: (a) ${ }^{13} \mathrm{C}$ NMR CP spectrum (125 MHz, $4 \mathrm{~mm}$ probe, $10 \mathrm{kHz}$ MAS frequency), (b) Proton SQ-TQ NMR spectrum (700 MHz, 2.5 $\mathrm{mm}$ probe, $18 \mathrm{kHz}$ MAS frequency). The trace above the 2D plot corresponds to the one-dimensional ${ }^{1} \mathrm{H}$-NMR spectrum. The dotted blue line corresponds to the $\omega_{1}=3 \omega_{2}$ diagonal. The dotted red circle underlines the autocorrelation of the hydride resonance. The experimental conditions are described in detail in the experimental section. The SQ-DQ correlation spectrum is shown in Figure S20.

EDX analysis showed a uniform distribution of Ta and Ir in the material (1.00 $\pm 0.06 \mathrm{Ir}: T a$ ratio - see Figure $\left.\mathrm{S}_{41}\right)$ and elemental analysis (Expected: Ir:Ta ratio $=1.0, \mathrm{C}:$ Ta ratio $=$ 15.0, Found: Ir:Ta ratio $=1.0$, C:Ta ratio $=13.1$ ) is in good agreement with the proposed formula for 6 .
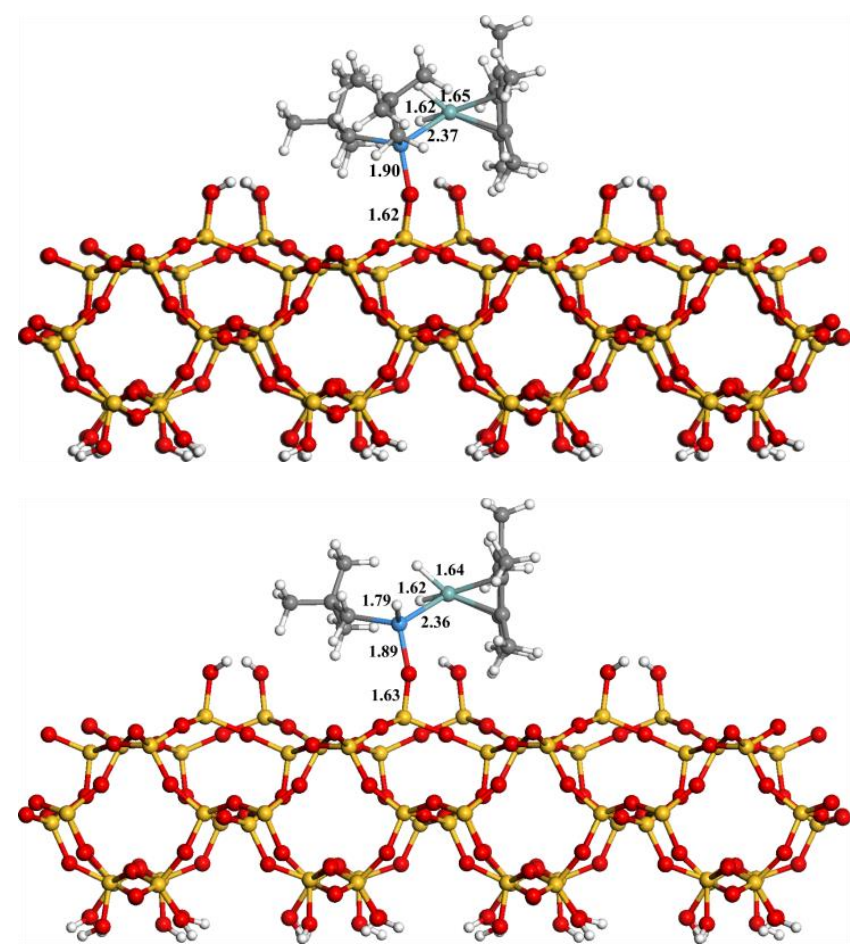

Figure 7. DFT optimized structures of the silica-supported complexes 5 (top) and 6 (bottom - model 6a; model $6 \mathrm{~b}$ in SI). Selected bond distances are given in $\AA$. Ta is represented in blue, $I r$ in green, $S i$ in yellow, $O$ in red, $C$ in grey and $H$ in white.

Periodic DFT calculations were used to gain further insights into the structures of the silica-supported species 5 and the complex $\mathbf{6}$ formed after exposure of 5 to $\mathrm{H}_{2}$ (see SI for computational details). Figure 7 (top) shows the most stable structure of $\mathbf{5}$. The Ta/Ir complex is anchored to the silica support through one $\mathrm{Ta}-\mathrm{O}-\mathrm{Si}$ interface bond ( $\mathrm{Ta}-\mathrm{O}$ bond is $1.90 \AA$, $\mathrm{Si}-\mathrm{O}$ bond is $1.62 \AA$ ). The Ta=Ir bond distance remains virtually unchanged upon deposition on silica. The Ir-H vibrational stretching modes were computed at 2056 and $2165 \mathrm{~cm}^{-1}$, which is 92 and $21 \mathrm{~cm}^{-1}$, respectively red-shifted as compared to the corresponding vibrations in the unsupported complex 1. Furthermore, two putative structures were obtained for the trihydride species $\mathbf{6}$. 
Model 6a (Figure 7-bottom) has one terminal Ta-H hydride bond of $1.785 \AA$ and two Ir-H terminal hydride bonds of 1.619 and $1.643 \AA$. The Ta=Ir metal-metal bond length in model 6a is $2.355 \AA$, virtually the same as in the dihydride precursor. Model $6 \mathbf{b}$ (Figure $\mathrm{S}_{31}$ in SI) contains three bridging $\mathrm{Ir}-\mathrm{H}-\mathrm{Ta}$ hydrides and a longer Ta-Ir distance of 2.595 $\AA$, and is $29.3 \mathrm{kcal}^{\mathrm{mol}} \mathrm{l}^{-1}$ less stable than model $\mathbf{6 a}$. The M$\mathrm{H}$ vibrational frequencies of $\mathbf{6 a}$ are computed at 1803 (Ta$\mathrm{H}), 2042$ (Ir-H) and 2149 (Ir-H) $\mathrm{cm}^{-1}$, in good agreement with the experimental values (see Table 1), as compared to those for model $\mathbf{6 b}\left(1705,1741\right.$ and $\left.2018 \mathrm{~cm}^{-1}\right)$. Taken in concert, these experimental and computational analyses are consistent with the proposed formula $\left[\equiv \operatorname{SiOTa}\left(\mathrm{CH}_{2}{ }^{t} \mathrm{Bu}\right) \mathrm{H}\left\{\mathrm{IrH}_{2}\left(\mathrm{Cp}^{*}\right)\right\}\right]$ for $\mathbf{6}$, although the partial formation of fully hydrogenated species cannot be ruled out.

Table 1. Selected structural parameters along with $\mathrm{M}-\mathrm{H}$ stretching frequencies obtained at the PBEo/def2-TZVP level. Experimental data are given in italic.

\begin{tabular}{|c|c|c|c|c|}
\hline Compound & Ta-Ir $(\AA)$ & $\begin{array}{l}\mathrm{Ir}-\mathrm{H} \\
(\AA)\end{array}$ & $\begin{array}{l}\mathrm{Ir}-\mathrm{Ta}-\mathrm{Cp}^{*} \text { cen- } \\
\text { troid }(\mathrm{deg})\end{array}$ & $\begin{array}{l}v(\mathrm{M}-\mathrm{H}) \\
\left(\mathrm{cm}^{-1}\right)\end{array}$ \\
\hline 1 & $\begin{array}{l}2.366 \\
2.3559(6)\end{array}$ & $\begin{array}{l}1.615 \\
1.618\end{array}$ & $\begin{array}{l}150.2 \\
151.3\end{array}$ & $\begin{array}{l}2148 \\
2186 \\
2056\end{array}$ \\
\hline 4 & $\begin{array}{l}2.465 \\
2.4443(3) \\
2.4575(4)\end{array}$ & 1.614 & $\begin{array}{l}137 \cdot 3 \\
136.7\end{array}$ & $\begin{array}{l}2180 \\
2090\end{array}$ \\
\hline 5 & 2.370 & $\begin{array}{l}1.621 \\
1.645\end{array}$ & 151.1 & $\begin{array}{l}2056 \\
2165 \\
2037 \\
2064\end{array}$ \\
\hline $6 a$ & 2.355 & $\begin{array}{l}1.619 \\
1.643\end{array}$ & 148.6 & $\begin{array}{l}1803 \\
2042 \\
2149 \\
1778 \\
1800 \\
1890 \\
2060\end{array}$ \\
\hline
\end{tabular}

\section{H/D EXCHANGE CATALYTIC ACTIVITY}

Complex $\mathbf{1}$ is stable in the solid-state and in hydrocarbon or ethereal solvents solutions up to $150^{\circ} \mathrm{C}$ for several hours. Although stable, complex 1 exhibits $\mathrm{H} / \mathrm{D}$ exchange reactivity. When a $\mathrm{C}_{6} \mathrm{D}_{6}$ solution of $\mathbf{1}$ is heated at $70^{\circ} \mathrm{C}$, concomitant disappearance of the ${ }^{1} \mathrm{H}$ NMR signals and appearance of ${ }^{2} \mathrm{H}$ NMR signals corresponding to the hydrides are observed (Figure $\mathrm{S}_{7}$ ). Note that the same phenomenon also occurs for the neopentyl and $\mathrm{Cp}^{*}$ ligands. This indicates that complex 1 can cleave $C-D$ bonds of $\mathrm{C}_{6} \mathrm{D}_{6}$ which ultimately leads to deuterium incorporation at every ligand positions in $\mathbf{1}$.

Scheme 6. Catalytic H/D exchange of fluorobenzene.

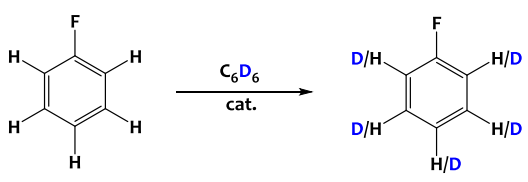

In light of this observation, we investigated the catalytic $\mathrm{H} / \mathrm{D}$ scrambling between $\mathrm{C}_{6} \mathrm{D}_{6}$ and $\mathrm{C}_{6} \mathrm{H}_{5} \mathrm{~F}$ (Scheme 6). Hydrogen Isotope Exchange (HIE) reactions are the most fundamental C-H functionalization processes, yet highly relevant for the industry for the direct incorporation of deuterium or tritium into organic substrates. $73-75$ Using $6 \mathrm{~mol} \%$ of 1, $74 \%$ conversion is reached after $24 \mathrm{~h}$ at $110^{\circ} \mathrm{C}$. Under the same experimental conditions, the siloxy and phenoxy derivatives, $\mathbf{2}$ and $\mathbf{3}$, as well as the tetrameric complex $\mathbf{4}$ display some catalytic activity, but all these species are less active than 1 (Table 2, entries 2-4 and Figure S35).

Table 2. Catalytic performances in hydrogen/deuterium exchange between $\mathrm{C}_{6} \mathrm{D}_{6}$ and $\mathrm{C}_{6} \mathrm{H}_{5} \mathrm{~F}$.

\begin{tabular}{|l|l|l|l|l|l|}
\hline $\begin{array}{c}\text { en- } \\
\text { try }\end{array}$ & catalyst & $\begin{array}{c}\text { loading } \\
(\mathrm{mol} \%)\end{array}$ & $\begin{array}{c}\mathrm{T} \\
\left({ }^{\circ} \mathrm{C}\right)\end{array}$ & $\begin{array}{c}\text { time } \\
(\mathrm{h})\end{array}$ & $\begin{array}{c}\text { conver- } \\
\text { sion }(\%)\end{array}$ \\
\hline 1 & $\mathbf{1}$ & 6 & 110 & 24 & 74 \\
\hline 2 & $\mathbf{2}$ & 6 & 110 & 24 & 8 \\
\hline 3 & 3 & 6 & 110 & 24 & 45 \\
\hline 4 & 4 & 6 & 110 & 24 & 58 \\
\hline 5 & $\mathbf{1}$ & 6 & 70 & 24 & 2 \\
\hline 6 & 5 & 6 & 70 & 24 & 70 \\
\hline 7 & 6 & 6 & 70 & 3 & 100 \\
\hline 8 & 6 & 0.2 & 70 & 24 & 70 \\
\hline 9 & 6 & 0.06 & 70 & 24 & 63 \\
\hline 10 & 6 & 0.06 & 70 & 61 & 90 \\
\hline 11 & {$\left[\left(\equiv \mathrm{SiO}_{2} \mathrm{TaH}_{\mathrm{x}}\right]\right.$} & 6 & 70 & 24 & 37 \\
\hline 12 & 6 & 6 & 25 & 3 & 97 \\
\hline
\end{tabular}

The reactions were performed in sealed glass containers using 0.077 $\mathrm{mmol} \mathrm{C}_{6} \mathrm{H}_{5} \mathrm{~F}$ in $0.58 \mathrm{~mL} \mathrm{C}_{6} \mathrm{D}_{6}$. Conversions were determined using ${ }^{1} \mathrm{H}$ and ${ }^{19} \mathrm{~F}$ NMR spectroscopy.

For sake of comparison, the starting monometallic precursors $\mathrm{Ta}\left(\mathrm{CH}^{t} \mathrm{Bu}\right)\left(\mathrm{CH}_{2}{ }^{ } \mathrm{Bu}\right)$ and $\mathrm{Cp}^{*} \mathrm{IrH}_{4}$ were also tested for this reaction but were found almost inactive. Note that $\mathrm{Ta}\left(\mathrm{CH}^{t} \mathrm{Bu}\right)\left(\mathrm{CH}_{2}{ }^{t} \mathrm{Bu}\right)$ does not exhibit any catalytic activity at temperatures varying from $25^{\circ} \mathrm{C}$ to $110^{\circ} \mathrm{C}$ whereas $\mathrm{CP}^{*} \mathrm{IrH}_{4}$ is catalytically inactive at $70^{\circ} \mathrm{C}$ and further decomposes above $110^{\circ} \mathrm{C}$ to form a black deposit of $\operatorname{Ir}(\mathrm{o})$ particles (observed by TEM and EDX, see Figure $\mathrm{S}_{43}$ ) showing some $\mathrm{H} / \mathrm{D}$ exchange activity after an induction period. Indeed, this deposit allows reaching a conversion of only $28 \%$ after $24 \mathrm{~h}$ at $110^{\circ} \mathrm{C}$. Therefore, the heterobimetallic species 1 exhibits enhanced activity and stability with respect to the corresponding monometallic precursors that we attribute to metal-metal synergy. The state of the art Crabtree's iridium catalyst, $\left[(\mathrm{COD}) \operatorname{Ir}\left(\mathrm{PCy}_{3}\right)(\mathrm{Py})\right]\left[\mathrm{PF}_{6}\right]$, which is one of the most popular catalyst for HIE reactions, ${ }^{73-75}$ was also tested and found catalytically inactive under these experimental conditions most likely due to its poor solubility in apolar solvents. 


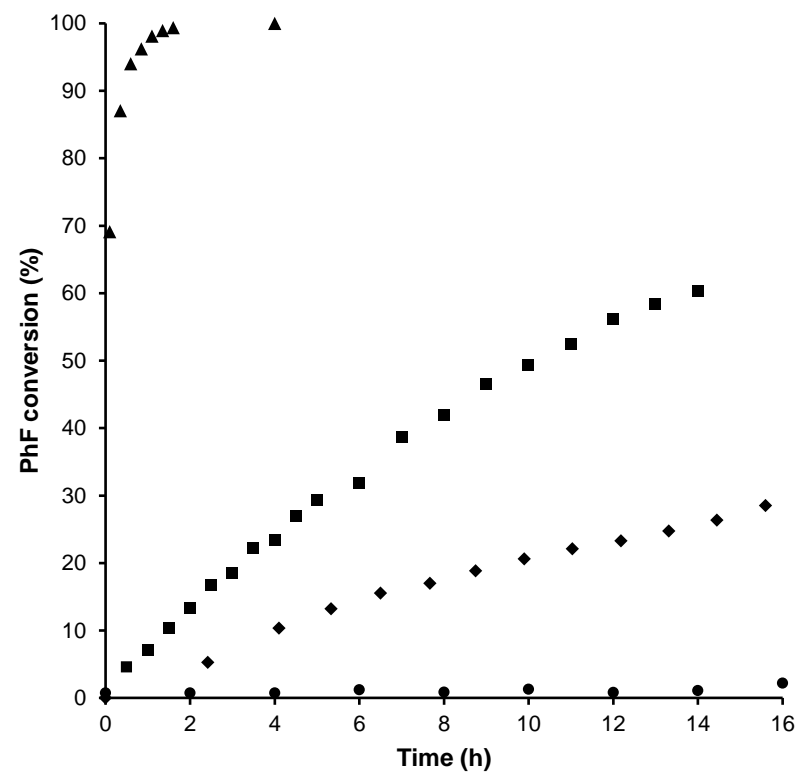

Figure 8. Conversion of fluorobenzene as a function of reaction time using: $\left[\left\{\left(\mathrm{CH}_{2}{ }^{t} \mathrm{Bu}\right)_{3} \mathrm{Ta}\right\}\left(\mathrm{Cp}^{*} \mathrm{IrH}_{2}\right)\right]$ complex 1 $(\bullet) ;\left[(\equiv \mathrm{SiO})_{2} \mathrm{TaH}\right]$ monometallic benchmark material $(\bullet)$; $\left[\equiv \operatorname{SiOTa}\left(\mathrm{CH}_{2}{ }^{t} \mathrm{Bu}\right)_{2}\left\{\operatorname{IrH}_{2}\left(\mathbf{C p}^{*}\right)\right\}\right]$ material 5 (घ); $\left[\equiv \operatorname{SiOTa}\left(\mathrm{CH}_{2}{ }^{t} \mathrm{Bu}\right) \mathrm{H}\left\{\mathrm{IrH}_{2}\left(\mathrm{Cp}^{*}\right)\right\}\right]$ material $6(\Delta)$. The H/D exchange experiments were carried out in $\mathrm{C}_{6} \mathrm{D}_{6}$ at $7^{\circ} \mathrm{C}$ with 6 mol\% of Ta.

The catalytic activity of the supported species $\mathbf{5}$ and $\mathbf{6}$ is substantially enhanced compared to that of the molecular analogues $1,2,3$ or 4 , and was thus scrutinized at lower temperature $\left(70^{\circ} \mathrm{C}\right) \cdot 70 \%$ conversion is achieved after $24 \mathrm{~h}$ using material $\mathbf{5}$ as catalyst, while the best homogeneous heterobimetallic catalyst, $\mathbf{1}$, only promotes $2 \%$ conversion under the same set of experimental conditions (Table 2 entries $7 v s$ 6). This drastic increase of catalytic performances upon grafting on support is remarkable because it involves only minor structural changes in the metals first coordination spheres upon immobilization. The increase in activity is even more dramatic in the case of 6 . Indeed, $98 \%$ conversion is reached with $\mathbf{6}$ within $\mathrm{th}$ of reaction whereas $\mathbf{1}$ only yields $1 \%$ conversion and $\mathbf{5 1 8 \%}$ conversion after an extended reaction time of $3 \mathrm{~h}$ (Figure 8). Silica-supported mononuclear zirconium and tantalum hydrides are reported to promote H/D exchange reactions..$^{76,77}$ We thus tested the monometallic silica-supported tantalum species $\left[(\equiv \mathrm{SiO}) \mathrm{Ta}\left(\mathrm{CH}^{t} \mathrm{Bu}\right)\left(\mathrm{CH}_{2}{ }^{t} \mathrm{Bu}\right)_{2}\right]^{78}$ and $\left[(\equiv \mathrm{SiO})_{2} \mathrm{TaH}_{\mathrm{x}}\right]^{70}$ as benchmarks for this reaction. $\left[(\equiv \mathrm{SiO}) \mathrm{Ta}\left(\mathrm{CH}^{t} \mathrm{Bu}\right)\left(\mathrm{CH}_{2}{ }^{t} \mathrm{Bu}\right)_{2}\right]$ is inactive, while $\left[(\equiv \mathrm{SiO})_{2} \mathrm{TaH}\right]$ has a low activity ( $7 \%$ conversion after $3 \mathrm{~h}$ at $70^{\circ} \mathrm{C}$, Table 2 entry 11 ), much lower than that of the supported heterobimetallic species $\mathbf{5}$ and $\mathbf{6}$ (Figure 8). This represents a two orders of magnitude increase in activity when compared to (i) the homogeneous $\mathrm{Ta} / \mathrm{Ir}$ systems as well as to (ii) the monometallic Ta supported systems. The unique molecular structure of the heterobimetallic hydride $\mathbf{6}$, which cannot be attained in solution, is most likely at the origin of such high reactivity.

Finally, the productivity and robustness of the heterogeneous catalyst 6 was evaluated using high substrate/catalyst ratio to determine the maximum accessible TON. After
61 hours at $70^{\circ} \mathrm{C}$ with as little as $0.06 \mathrm{~mol} \%$ of the supported catalyst 6 (Table 2, entry 10), a TON of 1422 and a TOF of 23,3 $\mathrm{h}^{-1}$ are found. At the same time, 6 is also active in mild conditions $\left(25^{\circ} \mathrm{C}\right)$ affording a conversion of $97 \%$ after 3 hours ( $6 \mathrm{~mol} \%$ catalyst, Table 2 entry 12 ). Examination of the site selectivity established that the $\mathrm{C}-\mathrm{H}$ activation occurs at similar rates at the ortho, para and meta positions and ultimately $100 \%$ deuterium incorporation is achieved after $2,6 \mathrm{~h}$ at $70^{\circ} \mathrm{C}$ with $6 \mathrm{~mol} \%$ catalyst. Importantly, the catalytic solid 6 was analyzed by HRTEM prior and after catalysis, excluding the formation of metal nanoparticles (see Figures $\mathrm{S}_{41}$ and $\mathrm{S}_{42}$ ). Split tests were carried out and no further conversion was detected after removal of the catalytic material by filtration, which indicates the absence of active metal species in solution. To further assess the absence of metal leaching during the catalytic tests, the reaction supernatants were analyzed by ICP and no traces of metal (<0.001 wt\% Ir, <0.02 wt\% Ta) were detected. This result confirms that the catalytic reaction occurs at the metal surface sites of the material, without any contribution of homogeneous pathways.
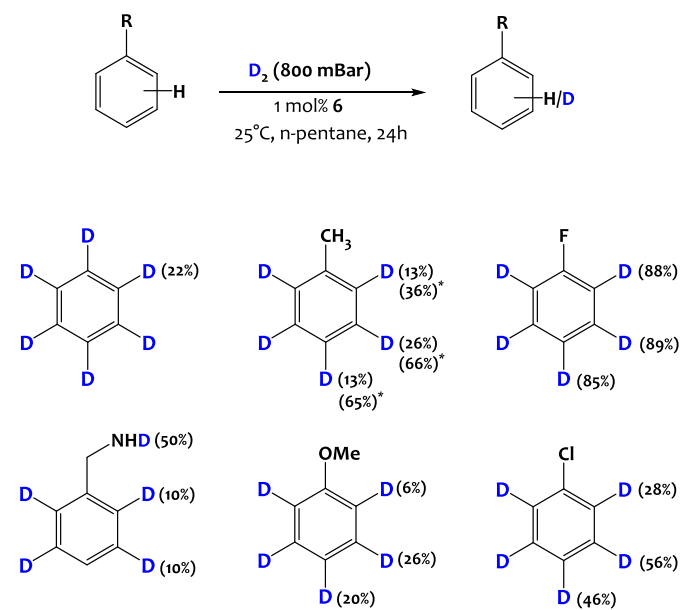

Figure 9. Deuterium labelling of representative arenes. Percentages in parentheses correspond to the extent of deuterium incorporation at the designated positions. * reaction was carried out at $70^{\circ} \mathrm{C}$.

$\mathrm{D}_{2}$ gas can be used as a more attractive isotope source in place of $\mathrm{C}_{6} \mathrm{D}_{6}$. Exposure of a $n$-pentane solution of $\mathrm{C}_{6} \mathrm{H}_{5} \mathrm{~F}$ to a $\mathrm{D}_{2}$ atmosphere (8oo mbar) in the presence of a catalytic amount (1 mol \%) of 6 leads to fast and extensive H/D exchange ( $92 \%$ conversion after $24 \mathrm{~h}$ at $25^{\circ} \mathrm{C}$ ). The substrate scope is not limited to fluorobenzene, and catalyst 6 is effective for $\mathrm{H} / \mathrm{D}$ exchange with a variety of functionalized arenes (Figure 9). The catalyst is selective for $s p_{2}$ hybridized $\mathrm{C}-\mathrm{H}$ bonds, while no deuterium incorporation is observed in $s p_{3} \mathrm{C}-\mathrm{H}$ bonds under mild conditions $\left(25^{\circ} \mathrm{C}\right.$ to $70^{\circ} \mathrm{C}$ ). This site-selectivity pattern has been reported previously for several H/D exchange catalysts. ${ }^{38,73,79,80}$ Quite remarkably, catalyst $\mathbf{6}$ is not deactivated by primary amines, and promotes deuterium incorporation at the arene ring of benzylamine. Extensive deuteration is also found at the N-position with this substrate. This catalytic system is therefore particularly robust and versatile. These preliminary $\mathrm{H} / \mathrm{D}$ exchange data involving $\mathrm{D}_{2}$ gas and $\mathbf{6}$ are 
thus very promising since efficient deuterium incorporation is achieved under mild conditions, without any additives, and using a heterogenized catalyst that can be easily separated from the products upon filtration. The catalytic performances of compound 6 reported in this work rivals those of the best catalytic systems known to date for this $\mathrm{H} / \mathrm{D}$ exchange reaction. ${ }^{38,73-75}$

\section{CONCLUSION}

In this contribution we reported a novel synthetic methodology to access highly reactive early/late heterobimetallic species, exemplified on a heterobimetallic Ta/Ir system. Through a surface organometallic chemistry approach, well-defined silica-supported low-coordinate Ta/Ir hydrido species were accessed and thoroughly characterized through a combination of techniques including advanced solid-state NMR studies. This approach allows access to unique low-coordinate species not achievable in solution by preventing undesired dimerization leading to the formation of higher nuclearity clusters. These original supported $\mathrm{Ta} / \mathrm{Ir}$ species exhibit drastically increased catalytic performances in H/D catalytic exchange reactions with respect to (i) monometallic analogues as well as (ii) homogeneous systems. In particular, material 6 promotes the $\mathrm{H} / \mathrm{D}$ exchange between fluorobenzene and $\mathrm{C}_{6} \mathrm{D}_{6}$ or $\mathrm{D}_{2}$ as deuterium sources with excellent productivity (TON up to 1422; TOF up to $\left.23,3 \mathrm{~h}^{-1}\right)$ under mild conditions $\left(25^{\circ} \mathrm{C}\right.$, subatmospheric $\mathrm{D}_{2}$ pressure) without any additives. Extension of this methodology to an expanded set of metal/metal couples to demonstrate the broader applicability of this strategy is currently underway in our laboratory.

\section{EXPERIMENTAL SECTION}

General considerations. Unless otherwise noted, all reactions were performed either using standard Schlenk line techniques or in an MBraun inert atmosphere glovebox under an atmosphere of purified argon $(<1 \mathrm{ppm}$ $\mathrm{O}_{2} / \mathrm{H}_{2} \mathrm{O}$ ). Glassware and cannulæ were stored in an oven at $\sim 100{ }^{\circ} \mathrm{C}$ for at least $12 \mathrm{~h}$ prior to use. Toluene and $n$-pentane were purified by passage through a column of activated alumina, dried over $\mathrm{Na}$ /benzophenone, vacuum-transferred to a storage flask and freeze-pump-thaw degassed prior to use. Deuterated solvents (THF- $d_{8}$, toluene- $d_{8}$ and $\mathrm{C}_{6} \mathrm{D}_{6}$ ) were dried over $\mathrm{Na}$ /benzophenone vacuum-transferred to a storage flask and freeze-pump-thaw degassed prior to use. Fluorobenzene was freeze-pump-thaw degassed and stored over molecular sieves $(4 \AA)$ prior to use. $\mathrm{Cp}^{*} \mathrm{IrH}_{4}{ }^{45}$ and $\mathrm{Ta}\left(\mathrm{CH}^{t} \mathrm{Bu}\right)\left(\mathrm{CH}_{2}{ }^{t} \mathrm{Bu}\right)_{3}{ }^{44}$ were prepared using literature procedures. The SBA-15 mesoporous silica was synthesized ${ }^{81}$ and dehydroxylated ${ }^{17}$ at $700^{\circ} \mathrm{C}$ according to the reported procedures (see SI for details). All other reagents were acquired from commercial sources and used as received. $\mathrm{D}_{2}$ and $\mathrm{H}_{2}$ gases were dried and deoxygenated over freshly regenerated R311G BASF catalyst/molecular sieves $(4 \AA)$ prior to use. For the synthesis and treatment of surface species, reactions were carried out using high-vacuum lines $\left(10^{-5} \mathrm{mBar}\right)$ and glovebox techniques. $n$-pentane was dried and stored over NaK, freeze-pump-thaw degassed and vacuum-transferred directly into the reaction vessel.

IR spectroscopy. Samples were prepared in a glovebox (diluted in $\mathrm{KBr}$ for 1, 2, 3 and 5; pure for $\mathbf{4}$ and $\mathbf{6}$ ), sealed under argon in a DRIFT cell equipped with $\mathrm{KBr}$ windows and analyzed on a Nicolet 670 FT-IR spectrometer. FT-IR (transmission) reactions monitoring under $\mathrm{H}_{2}$ or $\mathrm{D}_{2}$ atmosphere were performed on pelleted solids mounted in a cell fitted with $\mathrm{CaF}_{2}$ windows and designed for in-situ reactions under controlled atmosphere with a Nicolet $6700-F T-I R$ spectrometer.

TEM and STEM-HAADF were used to understand the structural and morphological characteristics of the catalysts by using a MET JEOL 210oF (FEG) microscope at the "Centre Technologiques des Micro-structures", CT $\mu$ Villeurbanne, France; equipped with an Oxford Instruments Energy-Dispersive Spec-troscopy (EDS) SDD detector.

Elemental analyses were performed under inert atmosphere either at the School of Human Sciences, Science Center, London Metropolitan University or at Mikroanalytisches Labor Pascher, Germany.

$\mathrm{X}$-ray structural determinations. Experimental details regarding XRD measurements are provided in SI. CCDC 1936789-1936792 contain the supplementary crystallographic data for this paper. These data are provided free of charge by the Cambridge Crystallographic Data Centre.

NMR Spectroscopy. Solution NMR spectra were recorded on Bruker AV-30o, AVQ-40o and AV-50o spectrometers. Chemical shifts were measured relative to residual solvent peaks, which were assigned relative to an external TMS standard set at $0.00 \mathrm{ppm} .{ }^{1} \mathrm{H}$ and ${ }^{13} \mathrm{C}$ NMR assignments were confirmed by ${ }^{1} \mathrm{H}-{ }^{1} \mathrm{H}$ COSY and ${ }^{1} \mathrm{H}-{ }^{13} \mathrm{C}$ HSQC and $\mathrm{HMBC}$ experiments. The spin-lattice relaxation time $\left(\mathrm{T}_{1}\right)$ measurements were recorded on a temperature range from $-45^{\circ} \mathrm{C}$ to $25^{\circ} \mathrm{C}$. The values were measured using the $180^{\circ}-\tau-90^{\circ}$ method (inversion-recovery). 14 values of $\tau$ were measured for each temperature, in the range of $1 \mathrm{~ms}$ to $4 \mathrm{~S}$. The carbon-13 solid-state NMR spectra were obtained on a Bruker $500 \mathrm{MHz}$ wide-bore spectrometer using a double resonance 4-mm MAS probe, while the proton solid-state NMR spectra were obtained on a Bruker 70o MHz narrowbore spectrometer using a double resonance 2.5 -mm MAS probe. The samples were introduced under argon in a zirconia rotor, which was then tightly closed. Dry nitrogen gas was used to spin the samples to avoid sample degradation. The ${ }^{13} \mathrm{C}$ spectra were obtained from cross polarization (CP) from protons using a linear ramped $\mathrm{CP}$ to optimize the magnetization transfer efficiency. A proton radio frequency (RF) field of $70 \mathrm{kHz}$ in the center of the ramp was applied, while the RF field on carbon-13 was adjusted for optimal sensitivity.

For all the proton multiple-quantum experiments, the spinning frequency was set to $18 \mathrm{kHz}$. The $2 \mathrm{D}$ proton DQSQ correlation spectra were recorded according to the following general scheme: excitation of DQ coherences, $t_{1}$ evolution, and reconversion into observable magnetiza- 
tion, Z-filter, and detection. DQ excitation and reconversion were achieved using the POST- $C_{7}$ pulse sequence..$^{82-84}$ The length of the POST-C $7^{85}$ excitation and reconversion block was set to $160 \mu$ s (corresponding to seven basic POST- $C_{7}$ cycles). Quadrature detection in $\omega_{1}$ was achieved using the States-TPPI method. ${ }^{86} \mathrm{~A}$ recycle delay of $1.5 \mathrm{~s}$ was used. A total of $80 t_{1}$ increments of $96 \mu$ s with 384 scans each were recorded. The total experimental time for the DQ experiments was $12 \mathrm{~h}$. The $2 \mathrm{D}$ proton TQ -SQ correlation spectra were recorded according to the following general scheme: excitation of TQ coherences, $t_{1}$ evolution, reconversion into observable magnetization, Z-filter, and detection. ${ }^{87-91}$ TQ excitation was achieved by the sequential application of first a $90^{\circ}$ proton pulse followed by a DQ POST- $C_{7}$ pulse sequence as previously described in the literature. The length of the POST- $\mathrm{C}_{7}$ excitation and reconversion block was set to $160 \mu$ s (corresponding to seven basic POST- $C_{7}$ cycles). Quadrature detection in $\omega 1$ was achieved using the States-TPPI method. ${ }^{86}$ A recycle delay of $1.5 \mathrm{~s}$ was used. A total of $128 \mathrm{t}$ increments of $32 \mu \mathrm{s}$ with 288 scans each were recorded. The total experimental time for the TQ experiment was $15 \mathrm{~h}$.

Synthesis of $\left[\left\{\mathrm{Ta}\left(\mathrm{CH}_{2}{ }^{t} \mathbf{B u}\right)_{3}\right\}\left\{\operatorname{IrH}_{\mathbf{2}}\left(\mathrm{CP}^{*}\right)\right\}\right]$ 1. A colorless pentane solution (30 mL) of $\mathrm{Cp}^{*} \mathrm{IrH}_{4}(300 \mathrm{mg}, 0.91 \mathrm{mmol}$, 1 eq.) was added dropwise to a dark-brown pentane solution (30 mL) of $\mathrm{Ta}\left(\mathrm{CH}^{\mathrm{t}} \mathrm{Bu}\right)\left(\mathrm{CH}_{2}{ }^{\mathrm{t}} \mathrm{Bu}\right)_{3}(42 \mathrm{O} \mathrm{mg}, 0.91 \mathrm{mmol}$, 1 eq.). The reaction mixture turned red and was stirred at room temperature for $2 \mathrm{~h}$. Volatiles were removed under vacuum affording pure $\mathbf{1}$ as an orange powder $(650 \mathrm{mg}$, $0.90 \mathrm{mmol}, 99 \%)$. Single crystals of $\mathbf{1}$ suitable for X-ray diffraction were grown upon sublimation under $10^{-5} \mathrm{mbar}$ vacuum. ${ }^{1} \mathrm{H}$ NMR $\left(400 \mathrm{MHz}, 293 \mathrm{~K}\right.$, toluene- $\left.d_{8}\right) \delta=2.16$ (s, $\left.{ }_{15} \mathrm{H}, \mathrm{Cp}^{*}\right), 1.28\left(\mathrm{~s}, 27 \mathrm{H},{ }^{\mathrm{t}} \mathrm{Bu}\right), 0.18\left(\mathrm{~s}, 6 \mathrm{H}, \mathrm{Ta}-\mathrm{CH}_{2}\right),-12.03(\mathrm{~s}$, $2 \mathrm{H}, \mathrm{Ir}-\mathrm{H}) .{ }^{1} \mathrm{H}$ NMR (300 MHz, $\left.293 \mathrm{~K}, \mathrm{C}_{6} \mathrm{D}_{6}\right) \delta=2.18(\mathrm{~s}, 15 \mathrm{H}$, $\left.\mathrm{CP}^{*}\right), 1.32(\mathrm{~s}, 27 \mathrm{H}, \mathrm{Bu}), 0.23\left(\mathrm{~s}, 6 \mathrm{H}, \mathrm{Ta}-\mathrm{CH}_{2}\right),-11.97(\mathrm{~s}, 2 \mathrm{H}$, Ir-H), ${ }^{1} \mathrm{H}$ NMR (300 MHz, 293K, THF- $\left.d_{8}\right) \delta=2.20\left(\mathrm{~s},{ }_{15} \mathrm{H}\right.$, $\left.\mathrm{Cp}^{*}\right), 1.18\left(\mathrm{~s}, 27 \mathrm{H},{ }^{\mathrm{t}} \mathrm{Bu}\right), 0.10\left(\mathrm{~s}, 6 \mathrm{H}, \mathrm{Ta}-\mathrm{CH}_{2}\right),-12.34(\mathrm{~s}, 2 \mathrm{H}$, Ir-H); ${ }^{13} \mathrm{C}\left\{{ }^{1} \mathrm{H}\right\}$ NMR (101 MHz, 293 K, $\left.\mathrm{C}_{6} \mathrm{D}_{6}\right) \delta=122.16(\mathrm{Ta}-$

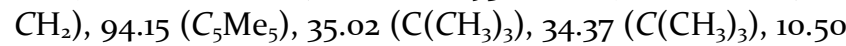
$\left(\mathrm{C}_{5} \mathrm{Me}_{5}\right)$. DRIFT $\left(293 \mathrm{~K}, \mathrm{~cm}^{-1}\right) \mathrm{v}=2950\left(\mathrm{~s}, \mathrm{v}_{\mathrm{C}-\mathrm{H}}\right), 2898\left(\mathrm{~s}, \mathrm{v}_{\mathrm{C}-}\right.$ H), $2859\left(\mathrm{~s}, v_{\mathrm{C}-\mathrm{H}}\right), 2751\left(\mathrm{~s}, v_{\mathrm{C}-\mathrm{H}}\right), 2056\left(\mathrm{~s}, \mathrm{v}_{\mathrm{Ir}-\mathrm{H}}\right), 1457(\mathrm{~s}), 1390$ ( s), $1380(\mathrm{~s}), 1361(\mathrm{~s}), 1255$ (s), $1229(\mathrm{~m}), 1069(\mathrm{~m}), 1031$ (s), $1004(\mathrm{~s}), 980(\mathrm{~s}), 932(\mathrm{~s}), 915(\mathrm{~m}), 768(\mathrm{~s}), 779(\mathrm{~s}), 757(\mathrm{~s})$, 614 (s). Elemental analysis calcd (\%) for $\mathrm{C}_{25} \mathrm{H}_{50}$ IrTa: $\mathrm{C} 41.48$, $\mathrm{H}$ 6.96; found: $\mathrm{C} 41.66, \mathrm{H}$ 7.0o.

Synthesis of $\left[\left\{\mathrm{Ta}\left(\mathrm{OSi}\left(\mathrm{O}^{t} \mathbf{B u}\right)_{3}\right)_{2}\left(\mathrm{CH}_{2}{ }^{t} \mathrm{Bu}\right)\right\}\left\{\mathrm{IrH}_{2}\left(\mathrm{Cp}^{*}\right)\right\}\right]$ 2. To a toluene solution $(5 \mathrm{~mL})$ of complex $1(46 \mathrm{mg}$, $0.06 \mathrm{mmol}, 1 \mathrm{eq}$.) was added dropwise a toluene solution $(5 \mathrm{~mL})$ of $\left[\mathrm{HOSi}\left(\mathrm{O}^{t} \mathrm{Bu}\right)_{3}\right]_{2}(33 \mathrm{mg}, 0.12 \mathrm{mmol}, 2$ eq. $)$ at room temperature. The solution was stirred 18 hours at $70^{\circ} \mathrm{C}$ leading to a pale yellow solution. Volatiles were removed under vacuum affording a yellow powder. The crude product was dissolved in the minimum amount of pentane and stored at $-40^{\circ} \mathrm{C}$ for 3 days to yield yellow crystals of 2 ( 55 $\mathrm{mg}, 0.05 \mathrm{mmol}, 80 \%$ ). Single crystals suitable for X-ray diffraction were obtained similarly. ${ }^{1} \mathrm{H}$ NMR $(400 \mathrm{MHz}, 293 \mathrm{~K}$, $\left.\mathrm{C}_{6} \mathrm{D}_{6}\right) \delta=2.33\left(\mathrm{~s}, 15 \mathrm{H}, \mathrm{Cp}^{*}\right), 1.52\left(\mathrm{~s}, 54 \mathrm{H}, \mathrm{O}^{\mathrm{t} B u}\right), 1.36(\mathrm{~s}, 9 \mathrm{H}$, $\left.\mathrm{CH}_{2}{ }^{\mathrm{t}} \mathrm{Bu}\right), 1.13\left(\mathrm{~s}, 2 \mathrm{H}, \mathrm{Ta}-\mathrm{CH}_{2}\right),-11.64(\mathrm{~s}, 2 \mathrm{H}, \mathrm{Ir}-\mathrm{H}) .{ }^{13} \mathrm{C}$ NMR
(101 MHz, 293K, $\left.\mathrm{C}_{6} \mathrm{D}_{6}\right) \delta=93.28\left(C_{5} \mathrm{Me}_{5}\right)$, $92.77\left(\mathrm{Ta}-\mathrm{CH}_{2}\right)$, $72.91\left(\mathrm{OC}\left(\mathrm{CH}_{3}\right)_{3}\right), 34.97\left(\mathrm{CH}_{2} \mathrm{C}\left(\mathrm{CH}_{3}\right)_{3}\right), 32.99\left(\mathrm{CH}_{2} \mathrm{C}\left(\mathrm{CH}_{3}\right)_{3}\right)$, $31.61\left(\mathrm{OC}\left(\mathrm{CH}_{3}\right)_{3}\right)$, $11.08\left(\mathrm{C}_{5} \mathrm{Me}_{5}\right)$. DRIFT $\left(293 \mathrm{~K}, \mathrm{~cm}^{-1}\right) \mathrm{v}=2973$ $\left(\mathrm{s}, v_{\mathrm{C}-\mathrm{H}}\right), 2930\left(\mathrm{~m}, \mathrm{v}_{\mathrm{C}-\mathrm{H}}\right), 2898\left(\mathrm{~m}, \mathrm{v}_{\mathrm{C}-\mathrm{H}}\right), 2871\left(\mathrm{w}, \mathrm{v}_{\mathrm{C}-\mathrm{H}}\right), 2022$ $\left(\mathrm{m}, \mathrm{v}_{\mathrm{Ir}-\mathrm{H}}\right), 1472(\mathrm{~m}), 1388(\mathrm{~s}), 1364(\mathrm{~s}), 1240(\mathrm{~s}), 1191$ (s), 1061 (s), 1027 (s), 1004 (s), 934 (s), 831 (s), $805(\mathrm{~m}), 703$ (m). Elemental analysis calcd (\%) for $\mathrm{C}_{39} \mathrm{H}_{82} \mathrm{O}_{8} \mathrm{Si}_{2}$ TaIr: $\mathrm{C} 42.26, \mathrm{H}$ 7.46; found: $\mathrm{C} 42.42, \mathrm{H} 7.43$.

Synthesis of $\left[\left\{\mathrm{Ta}(\mathrm{OAr})\left(\mathrm{CH}_{2}{ }^{t} \mathrm{Bu}\right)_{2}\right\}\left\{\mathrm{IrH}_{2}\left(\mathrm{C}^{*}\right)\right\}\right](\mathrm{OAr}=$ 2,6-diphenyl-phenoxy) 3. A pentane:toluene solution ( $8 \mathrm{~mL}, 7: 1$ ) of 2,6-diphenylphenol (69 mg, $0.28 \mathrm{mmol}, 1 \mathrm{eq}$ ) was added at room temperature to a $4 \mathrm{~mL}$ pentane solution of complex 1 (200 mg, $0.28 \mathrm{mmol}$, 1 eq.) under vigorous stirring. The reaction mixture was stirred for 2 hours at room temperature yielding an orange solution. The volatiles were removed in vacuo to yield 3 as an orange powder (238 mg, $0.27 \mathrm{mmol}, 96 \%$ ). Single crystals suitable for XRay diffraction were grown from a saturated solution of 3 in the minimum amount of pentane stored at $-40^{\circ} \mathrm{C}$ for 5 days. ${ }^{1} \mathrm{H}$ NMR $\left(400 \mathrm{MHz},{ }^{293} \mathrm{~K}, \mathrm{C}_{6} \mathrm{D}_{6}\right) \delta=7.73$ (dd, $\left.3_{\mathrm{HH}}=7.7 \mathrm{~Hz},{ }^{4} J_{\mathrm{HH}}=1.4 \mathrm{~Hz}, 4 \mathrm{H}, \mathrm{H}_{\mathrm{Ar}}\right), 7.33\left(\mathrm{~m},{ }^{3} J_{\mathrm{HH}}=7.7 \mathrm{~Hz}\right.$, $\left.4 \mathrm{H}, \quad \mathrm{H}_{\mathrm{Ar}}\right), 7.23\left(\mathrm{~d}, 33_{\mathrm{HH}}=7.8 \mathrm{~Hz}, 2 \mathrm{H}, \mathrm{H}_{\mathrm{Ar}}\right), 7.18(\mathrm{tt}$, $\left.3 J_{\mathrm{HH}}=7.7 \mathrm{~Hz},{ }^{4} J_{\mathrm{HH}}=1.3 \mathrm{~Hz}, 2 \mathrm{H}, \mathrm{H}_{\mathrm{Ar}}\right), 6.94\left(\mathrm{t}, 3 J_{\mathrm{HH}}=7.7 \mathrm{~Hz}\right.$, $\left.1 \mathrm{H}, \mathrm{H}_{\mathrm{Ar}}\right), 2.04,\left(\mathrm{~s}, 15 \mathrm{H}, \mathrm{Cp}^{*}\right), 1.05\left(\mathrm{~s}, 18 \mathrm{H},{ }^{\mathrm{t}} \mathrm{Bu}\right), 0.08(\mathrm{~d}$, $\left.{ }^{2} J_{\mathrm{HH}}=14.4 \mathrm{~Hz}, 2 \mathrm{H}, \mathrm{Ta}-\mathrm{CH}_{2}\right),-0.11\left(\mathrm{~d},{ }^{2} J_{\mathrm{HH}}=14.4 \mathrm{~Hz}, 2 \mathrm{H}, \mathrm{Ta}-\right.$ $\mathrm{CH}_{2}$ ), -11.33 (s, 2H, Ir-H). ${ }^{13} \mathrm{C}$ NMR (101 MHz, 293K, $\mathrm{C}_{6} \mathrm{D}_{6}$ ) $\delta=156.35\left(\mathrm{C}_{\mathrm{Ar}}\right), 139.74\left(\mathrm{C}_{\mathrm{Ar}}\right), 133.33\left(\mathrm{C}_{\mathrm{Ar}}\right), 130.83\left(\mathrm{C}_{\mathrm{Ar}}\right), 130.76$ $\left(\mathrm{C}_{\mathrm{Ar}}\right), 128.89\left(\mathrm{C}_{\mathrm{Ar}}\right), 127.67\left(\mathrm{C}_{\mathrm{Ar}}\right), 122.66\left(\mathrm{C}_{\mathrm{Ar}}\right), 111.96\left(\mathrm{Ta}-\mathrm{CH}_{2}\right)$, $94.18\left(C_{5} \mathrm{Me}_{5}\right), \quad 34.91 \quad\left(C\left(\mathrm{CH}_{3}\right)_{3}\right), \quad 33.58\left(\mathrm{C}\left(\mathrm{CH}_{3}\right)_{3}\right), \quad 10.81$ $\left(\mathrm{C}_{5} \mathrm{Me}_{5}\right)$. DRIFT $\left(293 \mathrm{~K}, \mathrm{~cm}^{-1}\right) 3053\left(\mathrm{~m}, \mathrm{v}_{\mathrm{C}-\mathrm{H}}\right), 3022\left(\mathrm{~m}, \mathrm{v}_{\mathrm{C}-\mathrm{H}}\right)$, $2951\left(\mathrm{~s}, v_{\mathrm{C}-\mathrm{H}}\right), 2892\left(\mathrm{~s}, v_{\mathrm{C}-\mathrm{H}}\right), 2854\left(\mathrm{~s}, v_{\mathrm{C}-\mathrm{H}}\right), 2762\left(\mathrm{~m}, v_{\mathrm{C}-\mathrm{H}}\right)$, $2094\left(\mathrm{~s}, v_{\mathrm{Ir}-\mathrm{H}}\right), 2054\left(\mathrm{~s}, v_{\mathrm{II}-\mathrm{H}}\right), 1453.2(\mathrm{~s}), 1415.2(\mathrm{~s}), 1381.8(\mathrm{~m})$, 1359.1 (m), 1246.4 (s), 1083.2 (m), 1029.0 (m), 918.0 (s), 803.5 $(\mathrm{w}), 758.9(\mathrm{~s}), 715.1(\mathrm{~m}), 702.6(\mathrm{~m}), 612.2(\mathrm{w})$. Elemental analysis calcd (\%) for $\mathrm{C}_{38} \mathrm{H}_{52} \mathrm{OIrTa}$ : $\mathrm{C}_{5} 0.66, \mathrm{H}_{5} .85$; found: $\mathrm{C}_{50.83}, \mathrm{H}_{5} .84$.

Synthesis of $\left[\left\{\mathrm{Ta}\left(\mathrm{CH}_{2}{ }^{t} \mathrm{Bu}\right)_{2}\right\}\left(\mathrm{Cp}^{*} \mathrm{IrH}\right)\right]_{2}$ 4. Complex 1 ( $150 \mathrm{mg}, 0.21 \mathrm{mmol}$, 1 eq.) was introduced in a $150 \mathrm{~mL}$ Schlenk flask and $6 \mathrm{~mL}$ of toluene were added at room temperature leading to a bright red solution. The solution was frozen in liquid nitrogen and vacuum was applied to the flask ( $10^{-5} \mathrm{mBar}$ ). A $\mathrm{H}_{2}$ atmosphere (750 mBar, 22 eq.) was then introduced at room temperature. The mixture was then heated at $80^{\circ} \mathrm{C}$ for 18 hours. The color turned from red to dark brown. The volatiles were removed under vacuum affording a dark yellow powder. Recrystallization from a pentane/toluene $(3 / 1)$ saturated solution at $-40^{\circ} \mathrm{C}$ yielded 4 as yellow crystals ( $45 \mathrm{mg}, 0.04 \mathrm{mmol}, 35 \%$ ). Single crystals suitable for $\mathrm{X}$-ray diffraction were grown similarly. ${ }^{1} \mathrm{H}$ NMR (400 MHz, $\left.293 \mathrm{~K}, \mathrm{C}_{6} \mathrm{D}_{6}\right) \delta=2.16\left(\mathrm{~s}, 30 \mathrm{H}, \mathrm{Cp}^{*}\right)$, $1.49\left(\mathrm{~s}, 36 \mathrm{H},{ }^{t} \mathrm{Bu}\right), 0.66\left(\mathrm{~d},{ }^{2} J_{\mathrm{HH}}=13 \mathrm{~Hz},{ }_{4} \mathrm{H}, \mathrm{Ta}-\mathrm{CH}_{2}\right),-0.68$ $\left(\mathrm{d},{ }^{2} \mathrm{~J}_{\mathrm{HH}}=13 \mathrm{~Hz}, 4 \mathrm{H}, \mathrm{Ta}-\mathrm{CH}_{2}\right)$, $-10.63(\mathrm{~s}, 2 \mathrm{H}, \mathrm{Ir}-\mathrm{H}) .{ }^{13} \mathrm{C}$ NMR (101 MHz, 293K, $\left.\mathrm{C}_{6} \mathrm{D}_{6}\right) \delta=123.22\left(\mathrm{Ta}-\mathrm{CH}_{2}\right), 97.38\left(C_{5} \mathrm{Me}_{5}\right)$, $35.89\left(\mathrm{C}\left(\mathrm{CH}_{3}\right)_{3}\right), 34.88\left(\mathrm{C}\left(\mathrm{CH}_{3}\right)_{3}\right), 10.51\left(\mathrm{C}_{5} \mathrm{Me}_{5}\right)$. DRIFT $\left(293 \mathrm{~K}, \mathrm{~cm}^{-1}\right) 2948\left(\mathrm{~s}, v_{\mathrm{C}-\mathrm{H}}\right), 2901\left(\mathrm{~s}, v_{\mathrm{C}-\mathrm{H}}\right), 2858\left(\mathrm{~s}, v_{\mathrm{C}-\mathrm{H}}\right), 2747$ $\left(\mathrm{m}, v_{\mathrm{C}-\mathrm{H}}\right), 2689\left(\mathrm{w}, v_{\mathrm{C}-\mathrm{H}}\right), 2090\left(\mathrm{~s}, v_{\mathrm{Ir}-\mathrm{H}}\right), 1460(\mathrm{~s}), 1381(\mathrm{~s}), 1357$ (4), $1233(\mathrm{~s}), 1079(\mathrm{w}), 1028(\mathrm{~m}), 982.7(\mathrm{w}), 936(\mathrm{~m}), 754(\mathrm{~m})$. Elemental analysis calcd (\%) for $\mathrm{C}_{40} \mathrm{H}_{76} \mathrm{Ir}_{2} \mathrm{Ta}_{2}: \mathrm{C}_{36.86, \mathrm{H}}$ 5.88; found: $\mathrm{C}_{37.21}, \mathrm{H} 5.85$. 
Preparation of $\left[\equiv \mathrm{SiOTa}\left(\mathrm{CH}_{2}{ }^{t} \mathrm{Bu}\right)_{2}\left\{\operatorname{IrH}_{2}\left(\mathrm{CP}^{*}\right)\right\}\right]$ 5. SBA$15_{700}$ (734 mg dehydroxylated at $700^{\circ} \mathrm{C}$ under $10^{-5} \mathrm{mBar}$ vacuum for 10 hours, $0.58 \mathrm{mmol}$ of $\mathrm{OH}$, 1.o eq.) is charged in one compartment of a two-sided Schlenk reaction vessel equipped with a sintered glass filter and complex 1 (492 mg, o.68 mmol, 1.2 eq.) is placed in the other compartment. The double-Schlenk vessel is then evacuated (10 $5 \mathrm{mBar}$ ) and dry pentane ( $15 \mathrm{~mL}$ ) is added to $\mathbf{1}$ via vacuum distillation. The red solution of complex $\mathbf{1}$ is transferred through the frit to the SBA-1570o powder and stirred at room temperature for $2 \mathrm{~h}$ upon which time the material turns pale yellow. After the reaction the pale red supernatant is filtered away from the solid. The solid is washed with fresh pentane and the supernatant is removed again. This procedure is repeated 6 times to ensure removal of any unreacted 1. The volatile components are then condensed in a 6.7 liters round bottom flask, propane (2.9 $\mathrm{mmol}$ ) is introduced as internal standard and the neopentane evolved during the grafting is quantified by G.C. (o. 58 mmol, 1.0 eq). The resulting pale yellow powder is dried under vacuum $\left(10^{-5} \mathrm{mBar}\right)$ for 2 hours at room temperature to yield $1.1 \mathrm{~g}$ of compound $5 .{ }^{1} \mathrm{H}$ MAS SSNMR $(500 \mathrm{MHz}$, $293 \mathrm{~K}) \delta=2.2\left(\mathrm{Cp}^{*}\right), 0.9\left(\mathrm{CH}_{2}{ }^{\mathrm{t}} \mathrm{Bu}\right),-11.5(\mathrm{Ir}-\mathrm{H}) .{ }^{13} \mathrm{C}$ CPMAS SSNMR $(126 \mathrm{MHz}, 293 \mathrm{~K}) \delta=107.5\left(C_{5} \mathrm{Me}_{5}\right), 93.9\left(\mathrm{Ta}-\mathrm{CH}_{2}\right)$, $33.5(\mathrm{t} B u)$, $9.1\left(\mathrm{C}_{5} \mathrm{Me}_{5}\right)$. DRIFT $\left(293 \mathrm{~K}, \mathrm{~cm}^{-1}\right) \mathrm{v}=2954\left(\mathrm{~s}, \mathrm{v}_{\mathrm{C}-\mathrm{H}}\right)$, $2905\left(\mathrm{~s}, v_{\mathrm{C}-\mathrm{H}}\right), 2866\left(\mathrm{~s}, v_{\mathrm{C}-\mathrm{H}}\right), 2769\left(\mathrm{w}, v_{\mathrm{C}-\mathrm{H}}\right), 2064\left(\mathrm{~s}, v_{\mathrm{Ir}-\mathrm{H}}\right)$, $2037\left(\mathrm{~s}, \mathrm{v}_{\mathrm{Ir}-\mathrm{H}}\right)$. Elemental analysis calcd (\%) for 5: C 12.60, H 2.07, Ir 10.13, Ta 9.54; found: $\mathrm{C}$ 12.49, $\mathrm{H}$ 2.01, Ir 10.2, Ta 9.27.

Preparation of $\left[\equiv \operatorname{SiOTa}\left(\mathrm{CH}_{2}{ }^{t} \mathrm{Bu}\right) \mathbf{H}\left\{\operatorname{IrH}_{2}\left(\mathrm{Cp}^{*}\right)\right\}\right] 6$. Compound 5 (195 mg, $0.1 \mathrm{mmol}$ of Ta) was placed in a $480 \mathrm{~mL}$ Schlenk flask and the argon atmosphere was replaced by a hydrogen atmosphere ( $950 \mathrm{mBar}, 180$ eq./Ta) at room temperature. The reactor was heated at $105^{\circ} \mathrm{C}$ for to hours and the solid material turned from pale yellow to brown. The gas phase was sampled to quantify by GC analysis the evolution of neopentane resulting from the hydrogenolysis of neopentyl ligands (o.9 Np/Ta). Compound 6 is obtained as a brown powder (141 mg). ${ }^{1} \mathrm{H}$ MAS SSNMR (500 $\mathrm{MHz}, 293 \mathrm{~K}) \delta=2.2\left(\mathrm{Cp}^{*}\right)$, $0.9\left(\mathrm{CH}_{2}{ }^{\mathrm{t}} \mathrm{Bu}\right)$, -10.0 to $-15.0(\mathrm{br}$, Ir-H). ${ }^{13} \mathrm{C}$ CPMAS SSNMR (126 MHz, 293K) $\delta=106.9$ $\left(\mathrm{C}_{5} \mathrm{Me}_{5}\right), 93.9\left(\mathrm{Ta}-\mathrm{CH}_{2}\right), 33.3\left({ }^{\mathrm{t}} \mathrm{Bu}\right), 8.9\left(\mathrm{C}_{5} \mathrm{Me}_{5}\right)$. DRIFT $\left(293 \mathrm{~K}, \mathrm{~cm}^{-1}\right) \mathrm{v}=2955\left(\mathrm{~s}, v_{\mathrm{C}-\mathrm{H}}\right), 2909\left(\mathrm{~s}, v_{\mathrm{C}-\mathrm{H}}\right), 2866\left(\mathrm{~s}, v_{\mathrm{C}-\mathrm{H}}\right)$, $2060\left(\mathrm{br}, v_{\mathrm{II}-\mathrm{H}}\right), 1890(\mathrm{~s}), 1800\left(\mathrm{~s}, v_{\text {Ta-H }}\right), 1778\left(\mathrm{~s}, v_{\text {Tа-H }}\right)$. Elemental analysis calcd (\%) for 6: C 9.78, H 1.59, Ir 10.43, Ta 9.80; found: C 8.51, H 1.25, Ir 10.70, Ta 9.78.

Treatment of 6 under $D_{2}$. In an argon glovebox, material 6 (10 $\mathrm{mg}$ ) was pelleted and the pellet was mounted in a cell (300 mL) equipped with $\mathrm{CaF}_{2}$ windows and designed for in-situ reactions monitoring under controlled atmosphere. Vacuum $\left(10^{-5} \mathrm{mBar}\right)$ was applied to the vessel and $\mathrm{D}_{2}$ (70o mBar) was then introduced into the cell at room temperature. A FT-IR (transmission) spectrum was recorded after 10 min at $25^{\circ} \mathrm{C}$. The spectrum showed a disappearance of the $v_{\text {Ta-H }}$ bands around $1800 \mathrm{~cm}^{-1}$. The $\mathrm{D}_{2}$ atmosphere was then evacuated $\left(10^{-5} \mathrm{mBar}\right)$ and replaced with a $\mathrm{H}_{2}$ atmosphere (70o mBar). After $10 \mathrm{~min}$ at $25^{\circ} \mathrm{C}$ reappearance of the $v_{\mathrm{Ta}-\mathrm{H}}$ stretches around $1800 \mathrm{~cm}^{-1}$ was observed in the FT-IR spectrum (Figure S27).
General procedure for catalytic hydrogen-deuterium exchange reaction.

(a) Using $\mathbf{C}_{6} \mathbf{D}_{6}$ as deuterium source: In a typical experiment, complex $6(3.3 \mathrm{mg}, 0.005 \mathrm{mmol}$ of Ta) was charged in a J. Young NMR tube and dissolved (or suspended for supported catalyst) in a stock solution composed of fluorobenzene $(7.4 \mathrm{mg}, 0.077 \mathrm{mmol})$, hexamethyldisiloxane $(5.8 \mathrm{mg}, 0.036 \mathrm{mmol})$ as internal standard and $\mathrm{C}_{6} \mathrm{D}_{6}(0.58 \mathrm{~mL})$. The reaction was then heated at $70^{\circ} \mathrm{C}$ inside a NMR spectrometer and periodically monitored by ${ }^{1} \mathrm{H}$ NMR and ${ }^{19} \mathrm{~F}$ NMR spectroscopy.

(b) Using $D_{2}$ as deuterium source: In a typical experiment, compound $6(5.5 \mathrm{mg}, 0.003 \mathrm{mmol}$ of Ta) was charged in a $25 \mathrm{~mL}$ J. Young sealed glass vessel equipped with a magnetic stir bar and suspended in a stock solution of fluorobenzene $(35.8 \mathrm{mg}, \quad 0.373 \mathrm{mmol})$ in $n$-octane $(0.30 \mathrm{~mL})$. The vessel was transferred outside of the Ar atmosphere glovebox and connected to a high-vacuum line. The suspension was frozen in liquid nitrogen and the $\mathrm{Ar}$ atmosphere was removed under dynamic vacuum. 800 mBar of $D_{2}$ were then introduced to the vessel and the solution was then thawed and stirred at $25^{\circ} \mathrm{C}$ for 24 hours. After the desired time reaction, the glass vessel was opened to air. The catalyst was removed by filtration through a glass microfiber filter. The filtrate was analyzed using quantitative ${ }^{1} \mathrm{H}$ NMR, ${ }^{2} \mathrm{H}$ NMR and ${ }^{19} \mathrm{~F}$ NMR spectroscopy in $\mathrm{CD}_{2} \mathrm{Cl}_{2}(0.3 \mathrm{~mL})$.

Split Test: Compound 6 (9.8 mg, $0.005 \mathrm{mmol} \mathrm{Ta}$ ) was charged in a J. Young NMR tube and suspended in a stock solution of fluorobenzene $(8.2 \mathrm{mg}, 0.085 \mathrm{mmol})$ and hexamethyldisiloxane $(6.4 \mathrm{mg}, 0.039 \mathrm{mmol})$ as internal standard in $\mathrm{C}_{6} \mathrm{D}_{6}(0.58 \mathrm{~mL})$. The solution was heated in a $70 \pm$ $2^{\circ} \mathrm{C}$ silicone oil bath and periodically monitored by ${ }^{1} \mathrm{H}$ NMR and ${ }^{19} \mathrm{~F}$ NMR spectroscopy. After 5 hours reaction (30\% conversion) the NMR tube was transferred to the Ar atmosphere glovebox. The supported catalyst was removed by filtration through a dry glass microfiber filter and the filtrate was transferred into another J. Young NMR tube which was again heated in a $70 \pm 2^{\circ} \mathrm{C}$ silicone oil bath and periodically monitored by ${ }^{1} \mathrm{H}$ NMR and ${ }^{19} \mathrm{~F}$ NMR spectroscopy. No further conversion (30\%) of fluorobenzene was observed after 48 hours. Analysis of this liquid filtrate by ICP showed the absence of Ta and Ir metals in solution. No metal nanoparticles were detected upon analysis of the spent solid catalyst by TEM.

Computational Details. Complexes 1 and 4 were optimized at the $\mathrm{PBEo}^{92} / \mathrm{def}_{2}$-TZVP93 level of density functional theory (DFT) using the Gaussian o9 software package. ${ }^{94}$ Quasi-relativistic Stuttgart-Dresden pseudopotentials were used for Ta and Ir. ${ }^{95}$ Additional benchmarking was performed with the following functionals: BP86, B3LYP, PBE, TPSS, TPSSh, Min and MilL as well as basis sets cc-pVTZ and def2-TZVPP, along with LANL2DZ pseudopotentials on Ta and Ir (Table S2 in the Supporting Information). Solvent effects of benzene were taken into account using the SMD implicit-solvation model. ${ }^{6}$ Frequency calculations on optimized geometries ensured that structures were minima (zero imaginary frequency) on the potential energy surface. 
Complete active space self-consistent field (CASSCF) ${ }^{97}$ method was used to analyze the nature of the metal-metal bond employing the MOLCAS 8.1 package $^{98}$ at the DFT/PBEo/def2-TZVP optimized geometry of complex 1 . Relativistic all electron ANO-RCC basis sets of triple-zeta quality (VTZP) were used for all atoms with the following contractions: 8s7p5d $3 \mathrm{f}_{2} \mathrm{~g} 1 \mathrm{~h}$ for Ta and Ir, 4s3p2dif for $\mathrm{C}$ and 3s2pid for H.99,100 Scalar relativistic effects were included using the Douglas-Kroll-Hess Hamiltonian. ${ }^{101}$ The complete active space contains ten electrons in ten active orbitals (10/10), comprising the $\sigma$ and $\pi$ Ta-Ir bonding orbitals and the corresponding antibonding orbitals, as well as the $\sigma \mathrm{Ir}-\mathrm{H}$ bonding and antibonding orbitals. The computational costs arising from the two-electron integrals were drastically reduced by employing the Cholesky decomposition (CD) technique ${ }^{102-104}$ combined with the Local Exchange (LK) screening. ${ }^{105}$

Periodic DFT calculations using the Vienna Ab-initio Simulation Package (VASP) ${ }^{106,107}$ were performed to further assess the structures of $\mathbf{5}$ and $\mathbf{6}$. A plane-wave basis set with an energy cutoff of $400 \mathrm{eV}$ was employed, along with the Perdew-Burke-Ernzerhof (PBE) exchange-correlation functional. ${ }^{108}$ The long-range weak dispersion interactions were taken into ac-count using the semi-empirical vdW method of Grimme DFT-D3. ${ }^{109}$ The electron-ion interactions were described by the projector augmented wave (PAW) method ${ }^{100}$ in the implementation of Kresse and Joubert." The atomic positions were optimized until the forces on all atoms were smaller than $0.02 \mathrm{eV} \AA^{-1}$ and the SCF convergence criteria is below $1 \times 10^{-5} \mathrm{eV}$. The Brillouin zone integration was sampled at the $\Gamma$-point, which is sufficient considering the size of the unit cells and the insulating nature of $\mathrm{SiO}_{2}$. The structure of hydroxylated silica with low coverage of $\mathrm{OH}$ groups $\left(1.75 \mathrm{~nm}^{-2}\right)$ was taken from the literature. ${ }^{112}$ A sufficiently large empty space between the two surfaces of the slab was chosen in the c-direction $(c=15 \AA)$ to avoid periodic artefacts resulting from interactions between the top and bottom surfaces. The vibrational frequencies were obtained within the harmonic approximation using the central finite difference method with 0.015 Å displacements in each Cartesian direction.

\section{ASSOCIATED CONTENT}

Supporting Information. $\mathrm{N}_{2}$ adsorption/desorption, NMR, IR, XRD, kinetic, electron microscopy and computational data. This material is available free of charge via the Internet at http://pubs.acs.org.

\section{AUTHOR INFORMATION}

\section{Corresponding Author}

* clement.camp@univ-lyonı.fr

\section{Author Contributions}

All authors have given approval to the final version of the manuscript.

\section{Funding Sources}

We gratefully acknowledge financial support from the "Programme Avenir Lyon Saint-Etienne de l'Université de Lyon”, as part of the "Investissements d'Avenir" program (ANR-11IDEX-0007), the CNRS-MOMENTUM program and the TGIR-RMN-THC Fr3050 CNRS.

\section{ACKNOWLEDGMENT}

We thank the "Centre de diffractométrie Henri Longchambon, Université de Lyon", and in particular Erwan Jeanneau for the single-crystal X-ray diffraction analyses. The calculations were performed using the HPC resources of GENCI (TGCC and CINES) through Grant 2018-810082.

\section{REFERENCES}

(1) Buchwalter, P.; Rosé, J.; Braunstein, P. Multimetallic Catalysis Based on Heterometallic Complexes and Clusters. Chem. Rev. 2015, 115 (1), 28-126.

(2) Mankad, N. P. Diverse Bimetallic Mechanisms Emerging from Transition Metal Lewis Acid/Base Pairs: Development of Co-Catalysis with Metal Carbenes and Metal Carbonyl Anions. Chem. Commun. 2018, 54 (11), 1291-1302.

(3) Powers, I. G.; Uyeda, C. Metal-Metal Bonds in Catalysis. ACS Catal. 2017, 7 (2), 936-958.

(4) Cooper, B. G.; Napoline, J. W.; Thomas, C. M. Catalytic Applications of Early/Late Heterobimetallic Complexes. Catal. Rev. 2012, 54 (1), 1-40.

(5) Bodio, E.; Picquet, M.; Le Gendre, P. "Early-Late" Heterobimetallic Catalysis and Beyond. In Topics in Organometallic Chemistry; Springer, Cham, 2015; Vol. 59, pp 139-186.

(6) Gade, L. H. Highly Polar Metal-Metal Bonds in "early-Late" Heterodimetallic Complexes. Angew. Chemie - Int. Ed. 2ooo, 39 (15), 2658-2678.

(7) Senocq, F.; Randrianalimanana, C.; Thorez, A.; Kalck, P.; Choukroun, R.; Gervais, D. A Novel Do-D8 Heterobimetallic Complex Obtained by Co-Ordination of a Zirconium(IV) Diphosphine to a Dinuclear Rhodium(I) Moiety Leading to a Hydroformylation-Active Species. J. Chem. Soc. Chem. Commun. 1984, 13 (20), 1376-1377.

(8) Gelmini, L.; Stephan, D. W. Preparation, Reactivity, Hydroformylation Catalysis, and Structural Studies of the Early Transition Metal/Late Transition Metal Heterobimetallic Complexes $\quad \mathrm{Cp} 2 \mathrm{M}(\mu-$ $\left.\mathrm{PR}_{2}\right)_{2} \mathrm{M}^{\prime} \mathrm{H}(\mathrm{CO}) \mathrm{PPh}_{3}\left(\mathrm{M}=\mathrm{Zr}\right.$, Hf; $\left.\mathrm{M}^{\prime}=\mathrm{Rh}, \mathrm{Ir}\right)$. Organometallics 1988, 7 (4), 849-855.

(9) Hostetler, M. J.; Bergman, R. G. Synthesis and Reactivity of Cp2Ta(CH2)2 $\operatorname{Ir}(\mathrm{CO})_{2}$ : An Early-Late Heterobimetallic Complex That Catalytically Hydrogenates, Isomerizes and Hydrosilates Alkenes. J. Am. Chem. Soc. 1990, 112 (23), 86218623.

(10) Zhou, W.; Marquard, S. L.; Bezpalko, M. W.; Foxman, B. M.; Thomas, C. M. Catalytic Hydrosilylation of Ketones Using a $\mathrm{Co} / \mathrm{Zr}$ Heterobimetallic Complex: Evidence for an Unusual Mechanism Involving Ketyl Radicals. Organometallics 2013, 32 (6), 1766-1772.

(11) Coombs, J.; Perry, D.; Kwon, D. H.; Thomas, C. M.; Ess, D. H. Why Two Metals Are Better Than One for Heterodinuclear Cobalt-Zirconium-Catalyzed Kumada Coupling. Organometallics 2018, 37 (22), 4195-4203.

Tsutsumi, H.; Sunada, Y.; Shiota, Y.; Yoshizawa, K.; Nagashima, H. Nickel(II), Palladium(II), and Platinum(II) H3-Allyl Complexes Bearing a Bidentate Titanium(IV) Phosphinoamide Ligand: A Ti M2Dative Bond Enhances the Electrophilieity of the $\pi$-Allyl. Organometallics 2009, 28 (7), 1988-1991.

Walker, W. K.; Kay, B. M.; Michaelis, S. A.; Anderson, D. L.; Smith, S. J.; Ess, D. H.; Michaelis, D. J. Origin of Fast Catalysis in Allylic Amination Reactions Catalyzed by Pd-Ti Heterobimetallic Complexes. J. Am. Chem. Soc. 2015, 137 (23), 7371-7378. 
Mazzacano, T. J.; Mankad, N. P. Base Metal Catalysts for Photochemical C-H Borylation That Utilize Metal-Metal Cooperativity. J. Am. Chem. Soc. 2013, 135 (46), 17258-17261. Cammarota, R. C.; Vollmer, M. V.; Xie, J.; Ye, J.; Linehan, J. C.; Burgess, S. A.; Appel, A. M.; Gagliardi, L.; Lu, C. C. A Bimetallic Nickel-Gallium Complex Catalyzes $\mathrm{CO}_{2}$ Hydrogenation via the Intermediacy of an Anionic Dio Nickel Hydride. J. Am. Chem. Soc. 2017, 139 (40), 1424414250.

Miyazaki, T.; Tanabe, Y.; Yuki, M.; Miyake, Y.; Nishibayashi, Y. Synthesis of Group IV ( $\mathrm{Zr}, \mathrm{Hf})$-Group VIII (Fe, Ru) Heterobimetallic Complexes Bearing Metallocenyl Diphosphine Moieties and Their Application to Catalytic Dehydrogenation of Amine-Boranes. Organometallics 2011, 30 (8), 2394-2404.

Copéret, C.; Comas-Vives, A.; Conley, M. P.; Estes, D. P.; Fedorov, A.; Mougel, V.; Nagae, H.; Núñez-Zarur, F.; Zhizhko, P. A. Surface Organometallic and Coordination Chemistry toward Single-Site Heterogeneous Catalysts: Strategies, Methods, Structures, and Activities. Chem. Rev. 2016, 116 (2), 323-421.

Copéret, C.; Estes, D. P.; Larmier, K.; Searles, K. Isolated Surface Hydrides: Formation, Structure, and Reactivity. Chem. Rev. 2016, 116 (15), 8463-8505.

Vidal, V.; Theolier, A.; Thivolle-Cazat, J.; Basset, J.-M. Metathesis of Alkanes Catalyzed by Silica-Supported Transition Metal Hydrides. Science (80-. ). 1997, 276 (5309), 99-102.

Avenier, P.; Taoufik, M.; Lesage, A.; Solans-Monfort, X.; Baudouin, A.; de Mallmann, A.; Veyre, L.; Basset, J.-M.; Eisenstein, O.; Emsley, L.; Quadrelli, E. A. Dinitrogen Dissociation on an Isolated Surface Tantalum Atom. Science (80-. ). 2007, 317 (5841), 1056-1060.

Weiss, K.; Guthmann, W.; Maisuls, S. Heterogeneous, Bimetallic Metathesis Catalysts by Reaction of Fischer-Type Carbene Complexes with Reduced Phillips Catalyst. Angew. Chemie Int. Ed. 1988, 27 (2), 275-277.

Samantaray, M. K.; Kavitake, S.; Morlanés, N.; Abou-Hamad, E.; Hamieh, A.; Dey, R.; Basset, J.-M. Unearthing a WellDefined Highly Active Bimetallic W/Ti Precatalyst Anchored on a Single Silica Surface for Metathesis of Propane. J. Am. Chem. Soc. 2017, 139 (9), 3522-3527.

Samantaray, M. K.; Dey, R.; Kavitake, S.; Abou-Hamad, E. Bendjeriou-Sedjerari, A.; Hamieh, A.; Basset, J.-M. Synergy between Two Metal Catalysts: A Highly Active SilicaSupported Bimetallic W/Zr Catalyst for Metathesis of $n$ Decane. J. Am. Chem. Soc. 2016, 138 (27), 8595-8602.

Rice, G. L.; Scott, S. L. Nonhydrolytic Surface Synthesis of a Heterobimetallic V-Ti Alkoxide Complex on Silica. Chem. Mater. 1998, 10 (2), 620-625.

Rataboul, F.; Copéret, C.; Lefort, L.; De Mallmann, A.; Thivolle-Cazat, J.; Basset, J. M. Synthesis, Characterization and Propane Metathesis Activity of a Tantalum-Hydride Prepared on High Surface Area "Silica Supported Zirconium Hydroxide." J. Chem. Soc. Dalt. Trans. 2007, 9 (9), 923-927. Schrekker, H. S.; Kotov, V.; Preishuber-Pflugl, P.; White, P.; Brookhart, M. Efficient Slurry-Phase Homopolymerization of Ethylene to Branched Polyethylenes Using $\alpha$-Diimine Nickel(II) Catalysts Covalently Linked to Silica Supports. Macromolecules 2006, 39 (19), 6341-6354.

Preishuber-Pflugl, P.; Brookhart, M. Highly Active Supported Nickel Diimine Catalysts for Polymerization of Ethylene. Macromolecules 20o2, 35 (16), 6074-6076.

Fu, X.; Zhang, L.; Tanaka, R.; Shiono, T.; Cai, Z. Highly Robust Nickel Catalysts Containing Anilinonaphthoquinone Ligand for Copolymerization of Ethylene and Polar Monomers. Macromolecules 2017, 50 (23), 9216-9221.

Choplin, A.; Huang, L.; Theolier, A.; Gallezot, P.; Basset, J. M.; Siriwardane, U.; Shore, S. G.; Mathieu, R. Formation of $\mathrm{Fe}-\mathrm{Os}$, Fc-Ru, and Fe-Co Bimetallic Particles by Thermal Decomposition of Heteropolynuclear Clusters Supported on a Partially Dehydroxylated Magnesia. J. Am. Chem. Soc. 1986, 108 (14), 4224-4225.

(30) Budge, J. R.; Scott, J. P.; Gates, B. C. Synthesis and Characterisation of an Alumina-Supported RuOs3 Cluster Catalyst. J. Chem. Soc. Chem. Commun. 1983, 12 (7), 342-343. (31) Héroguel, F.; Gebert, D.; Detwiler, M. D.; Zemlyanov, D. Y.; Baudouin, D.; Copéret, C. Dense and Narrowly Distributed Silica-Supported Rhodium and Iridium Nanoparticles: Preparation via Surface Organometallic Chemistry and Chemisorption Stoichiometry. J. Catal. 2014, 316, 260-269.

(32) Héroguel, F.; Siddiqi, G.; Detwiler, M. D.; Zemlyanov, D. Y.; Safonova, O. V.; Copéret, C. Simultaneous Generation of Mild Acidic Functionalities and Small Supported Ir NPs from Alumina-Supported Well-Defined Iridium Siloxide. J. Catal. 2015, 321, 81-89.

(33) Samantaray, M. K.; Alauzun, J.; Gajan, D.; Kavitake, S.; Mehdi, A.; Veyre, L.; Lelli, M.; Lesage, A.; Emsley, L.; Copéret, C.; Thieuleux, C. Evidence for Metal-Surface Interactions and Their Role in Stabilizing Well-Defined Immobilized Ru-NHC Alkene Metathesis Catalysts. J. Am. Chem. Soc. 2013, 135 (8), 3193-3199.

(34) Romanenko, I.; Gajan, D.; Sayah, R.; Crozet, D.; Jeanneau, E.; Lucas, C.; Leroux, L.; Veyre, L.; Lesage, A.; Emsley, L.; Lacôte, E.; Thieuleux, C. Iridium(I)/N-Heterocyclic Carbene Hybrid Materials: Surface Stabilization of Low-Valent Iridium Species for High Catalytic Hydrogenation Performance. Angew. Chemie Int. Ed. 2015, 54 (44), 12937-12941.

(35) Maishal, T. K.; Alauzun, J.; Basset, J.-M.; Copéret, C.; Corriu, R. J. P.; Jeanneau, E.; Mehdi, A.; Reyé, C.; Veyre, L.; Thieuleux, C. A Tailored Organometallic-Inorganic Hybrid Mesostructured Material: A Route to a Well-Defined, Active, and Reusable Heterogeneous Iridium-NHC Catalyst for H/D Exchange. Angew. Chemie Int. Ed. 2008, 47 (45), 8654-8656. (36) Maishal, T. K.; Boualleg, M.; Bouhrara, M.; Copéret, C.; Jeanneau, E.; Veyre, L.; Thieuleux, C. Domination of Local Environment over Pore Confinement Effects on the Catalytic Performances of Single-Site Cp*IrIII-NHC Heterogeneous vs. Homogeneous H/D Exchange Catalysts. Eur. J. Inorg. Chem. 2010, 2010 (31), 5005-5010.

(37) Klet, R. C.; Kaphan, D. M.; Liu, C.; Yang, C.; Kropf, A. J.; Perras, F. A.; Pruski, M.; Hock, A. S.; Delferro, M. Evidence for Redox Mechanisms in Organometallic Chemisorption and Reactivity on Sulfated Metal Oxides. J. Am. Chem. Soc. 2018, 140 (20), 6308-6316.

(38) Kaphan, D. M.; Klet, R. C.; Perras, F. A.; Pruski, M.; Yang, C.; Kropf, A. J.; Delferro, M. Surface Organometallic Chemistry of Supported Iridium(III) as a Probe for Organotransition Metal-Support Interactions in C-H Activation. ACS Catal. 2018, 8 (6), 5363-5373.

(39) Culver, D. B.; Tafazolian, H.; Conley, M. P. A Bulky Pd(II) $\alpha-$ Diimine Catalyst Supported on Sulfated Zirconia for the Polymerization of Ethylene and Copolymerization of Ethylene and Methyl Acrylate. Organometallics 2018, 37 (6), 1001-1006.

(40) Tafazolian, H.; Culver, D. B.; Conley, M. P. A Well-Defined $\mathrm{Ni}(\mathrm{II}) \alpha$-Diimine Catalyst Supported on Sulfated Zirconia for Polymerization Catalysis. Organometallics 2017, 36 (13), 2385-2388.

(41) Butovskii, M. V.; Döring, C.; Bezugly, V.; Wagner, F. R.; Grin, Y.; Kempe, R. Molecules Containing Rare-Earth Atoms Solely Bonded by Transition Metals. Nat. Chem. 2010, 2 (9), 741-744.

(42) Francis, B. R.; Green, M. L. H.; Luong-Thi, T.; Moser, G. A. Preparation and Reactions of Cyclo-Tetra- $\mu$-LithioTetrakis[Bis( $\eta$-Cyclo-Pentadienyl)Hydrido-Molybdenum] and -Tungsten] and Some $\operatorname{Bis}(\eta$-Cyclopentadienyl) Derivatives of Molybdenum and Tungsten. J. Chem. Soc. Dalt. Trans. 1976, 4 (14), 1339-1345.

(43) Golden, J. T.; Peterson, T. H.; Holland, P. L.; Bergman, R. G.; Andersen, R. A. Adduct Formation and Single and Double Deprotonation of $\mathrm{CP}^{*}(\mathrm{PMe} 3) \operatorname{Ir}(\mathrm{H}) 2$ with Main Group Metal 
Alkyls and Aryls: Synthesis and Structure of Three Novel Ir$\mathrm{Al}$ and Ir-Mg Heterobimetallics. J. Am. Chem. Soc. 1998, 120 (1), 223-224.

(44) Schrock, R. R.; Fellmann, J. D. Multiple Metal-Carbon Bonds. 8. Preparation, Characterization, and Mechanism of Formation of the Tantalum and Niobium Neopentylidene Complexes, $\mathrm{M}\left(\mathrm{CH}_{2} \mathrm{CMe}_{3}\right)_{3}\left(\mathrm{CHCMe}_{3}\right)$. J. Am. Chem. Soc. 1978, 100 (11), 3359-3370.

(45) Gilbert, T. M.; Hollander, F. J.; Bergman, R. G. (Pentamethylcyclopentadienyl)Iridium Polyhydride Complexes: Synthesis of Intermediates in the Mechanism of Formation of (Pentamethylcyclopentadienyl)Iridium Tetrahydride and the Preparation of Several Iridium(V) Compounds. J. Am. Chem. Soc. 1985, 107 (12), 3508-3516.

(46) Goldberg, J. M.; Goldberg, K. I.; Heinekey, D. M.; Burgess, S. A.; Lao, D. B.; Linehan, J. C. Detection of an IridiumDihydrogen Complex: A Proposed Intermediate in Ionic Hydrogenation. J. Am. Chem. Soc. 2017, 139 (36), 1263812646.

(47) Rozenel, S. S.; Padilla, R.; Camp, C.; Arnold, J. Unusual Activation of $\mathrm{H}_{2}$ by Reduced Cobalt Complexes Supported by a PNP Pincer Ligand. Chem. Commun. 2014, 50 (20), 26122614 .

(48) Heinekey, D. M.; Fine, D. A.; Harper, T. G. P.; Michel, S. T. Dinuclear Dihydride Complexes of Iridium: A Study of Structure and Dynamics. Can. J. Chem. 1995, 73 (7), 1116-1125.

(49) Wax, M. J.; Stryker, J. M.; Buchanan, J. M.; Kovac, C. A.; Bergman, R. G. Reversible $\mathrm{C}-\mathrm{H}$ Insertion/Reductive Elimination in

$\left(\mathrm{H}_{5}-\right.$ Pentamethylcyclopentadienyl)(Trimethylphosphine)Iridium Complexes. Use in Determining Relative MetalCarbon Bond Energies and Thermally Activating Methane. J. Am. Chem. Soc. 1984, 106 (4), 1121-1122.

(50) Gilbert, T. M.; Bergman, R. G. Synthesis of Trimethylphosphine-Substituted

(Pentamethylcyclopentadienyl)Iridium Hydride Complexes; Protonation and Deprotonation of

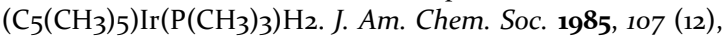
3502-3507.

(51) White, C.; Oliver, A. J.; Maitlis, P. M. Pentamethylcyclopentadienyl-Rhodium and -Iridium Complexes. Part VII. Mono-, Di-, and Tri- $\mu$-HydridoComplexes. J. Chem. Soc. Dalt. Trans. 1973, 3 (18), 1901-1907.

(52) Hostetler, M. J.; Butts, M. D.; Bergman, R. G. Rate and Equilibrium Study of the Reversible Oxidative Addition. Organometallics 1993, 12 (6), 65-75.

(53) Oishi, M.; Kino, M.; Saso, M.; Oshima, M.; Suzuki, H. EarlyLate Heterobimetallic Complexes with a Ta-Ir Multiple Bond: Bimetallic Oxidative Additions of $\mathrm{C}-\mathrm{H}, \mathrm{N}-\mathrm{H}$, and $\mathrm{O}-$ H Bonds. Organometallics 2012, 31 (13), 4658-4661.

(54) Yamamoto, K.; Higashida, K.; Nagae, H.; Tsurugi, H.; Mashima, K. Synthesis and Characterization of Heterobimetallic Tantalum-Rhodium and TantalumIridium Complexes Connected by a Tantalacyclopentadiene Fragment. Helv. Chim. Acta 2016, 99 (11), 848-858.

(55) Pauling, L. Atomic Radii and Interatomic Distances in Metals. J. Am. Chem. Soc. 1947, 69 (3), 542-553.

(56) Cotton, F. A.; Murillo, C. A.; Walton, R. A. Multiple Bonds between Metal Atoms, 3rd ed.; Cotton, F. A., Murillo, C. A., Walton, R. A., Eds.; Springer Science and Business Media: New York, USA, 2005.

(57) Guggenberger, L. J.; Schrock, R. R. A Tantalum Carbyne Complex. J. Am. Chem. Soc. 1975, 97 (10), 2935.

(58) Srivastava, R.; Moneuse, R.; Petit, J.; Pavard, P. A.; Dardun, V.; Rivat, M.; Schiltz, P.; Solari, M.; Jeanneau, E.; Veyre, L.; Thieuleux, C.; Quadrelli, E. A.; Camp, C. Early/Late Heterobimetallic Tantalum/Rhodium Species Assembled Through a Novel Bifunctional NHC-OH Ligand. Chem. - A Eur. J. 2018, 24 (17), 4361-4370.

(59) Blanc, F.; Copéret, C.; Thivolle-Cazat, J.; Basset, J. M.; Lesage, A.; Emsley, L.; Sinha, A.; Schrock, R. R. Surface versus
Molecular Siloxy Ligands in Well-Defined Olefin Metathesis Catalysts: $\quad\left[\left\{(\mathrm{RO})_{3} \mathrm{SiO}\right\} \mathrm{Mo}(=\mathrm{NAr})(=\mathrm{CHtBu})(\mathrm{CH} 2 \mathrm{tBu})\right]$. Angew. Chemie - Int. Ed. 2006, 45 (8), 1216-1220.

(6o) Mougel, V.; Copéret, C. Isostructural Molecular and Surface Mimics of the Active Sites of the Industrial $\mathrm{WO}_{3} / \mathrm{SiO}_{2}$ Metathesis Catalysts. ACS Catal. 2015, 5 (11), 6436-6439.

(61) Murugavel, R.; Voigt, A.; Walawalkar, M. G.; Roesky, H. W. Hetero- and Metallasiloxanes Derived from Silanediols, Disilanols, Silanetriols, and Trisilanols. Chem. Rev. 1996, 96 (6), 2205-2236.

(62) Camp, C.; Kefalidis, C. E.; Pécaut, J.; Maron, L.; Mazzanti, M. Controlled Thermolysis of Uranium (Alkoxy)Siloxy Complexes: A Route to Polymetallic Complexes of LowValent Uranium. Angew. Chemie - Int. Ed. 2013, 52 (48), 12646-12650.

(63) Mougel, V.; Camp, C.; Pécaut, J.; Copéret, C.; Maron, L.; Kefalidis, C. E.; Mazzanti, M. Siloxides as Supporting Ligands in Uranium(III)-Mediated Small-Molecule Activation. Angew. Chemie - Int. Ed. 2012, 51 (49), 12280-12284.

(64) Camp, C.; Pécaut, J.; Mazzanti, M. Tuning UraniumNitrogen Multiple Bond Formation with Ancillary Siloxide Ligands. J. Am. Chem. Soc. 2013, 135 (32), 12101-12111.

(65) Camp, C.; Mougel, V.; Pécaut, J.; Maron, L.; Mazzanti, M. Cation-Mediated Conversion of the State of Charge in Uranium Arene Inverted-Sandwich Complexes. Chem. - A Eur. J. 2013, 19 (51), 17528-17540.

(66) Brown, S. P. Probing Proton-Proton Proximities in the Solid State. Prog. Nucl. Magn. Reson. Spectrosc. 2007, 50 (4), 199251.

(67) Rataboul, F.; Baudouin, A.; Thieuleux, C.; Veyre, L.; Copéret, C.; Thivolle-Cazat, J.; Basset, J.-M.; Lesage, A.; Emsley, L. Molecular Understanding of the Formation of Surface Zirconium Hydrides upon Thermal Treatment under Hydrogen of [([Triple Bond $\left.] \mathrm{SiO}) \mathrm{Zr}\left(\mathrm{CH}_{2} \mathrm{tBu}\right)_{3}\right]$ by Using Advanced Solid-State NMR Techniques. J. Am. Chem. Soc. 2004, 126 (39), 12541-12550.

(68) Chen, Y.; Ould-Chikh, S.; Abou-Hamad, E.; Callens, E.; Mohandas, J. C.; Khalid, S.; Basset, J.-M. Facile and Efficient Synthesis of the Surface Tantalum Hydride (三SiO) 2 Ta III H and Tris-Siloxy Tantalum ( $\equiv \mathrm{SiO}) 3$ Ta III Starting from Novel Tantalum Surface Species ( $\equiv \mathrm{SiO}) \mathrm{TaMe} 4$ and $(\equiv \mathrm{SiO}) 2 \mathrm{TaMe}$ 3. Organometallics 2014, 33 (5), 1205-1211.

(69) Vidal, V.; Théolier, A.; Thivolle-Cazat, J.; Basset, J.-M.; Corker, J. Synthesis, Characterization, and Reactivity, in the C-H Bond Activation of Cycloalkanes, of a Silica-Supported Tantalum(III) Monohydride Complex: (:SiO) 2 Ta III -H. J. Am. Chem. Soc. 1996, 118 (19), 4595-4602.

(7o) Soignier, S.; Taoufik, M.; Le Roux, E.; Saggio, G.; Dablemont, C.; Baudouin, A.; Lefebvre, F.; De Mallmann, A.; ThivolleCazat, J.; Basset, J. M.; Sunley, G.; Maunders, B. M. Tantalum Hydrides Supported on MCM-41 Mesoporous Silica: Activation of Methane and Thermal Evolution of the Tantalum-Methyl Species. Organometallics 20o6, 25 (7), 1569-1577.

(71) Cadars, S.; Lesage, A.; Emsley, L. Chemical Shift Correlations in Disordered Solids. J. Am. Chem. Soc. 2005, 127 (12), 44664476.

(72) Sakellariou, D.; Brown, S. P.; Lesage, A.; Hediger, S.; Bardet, M.; Meriles, C. A.; Pines, A.; Emsley, L. High-Resolution NMR Correlation Spectra of Disordered Solids. J. Am. Chem. Soc. 2003, 125 (14), 4376-4380.

(73) Pony Yu, R.; Hesk, D.; Rivera, N.; Pelczer, I.; Chirik, P. J. IronCatalysed Tritiation of Pharmaceuticals. Nature 2016, 529 (7585), 195-199.

(74) Brown, J. A.; Cochrane, A. R.; Irvine, S.; Kerr, W. J.; Mondal, B.; Parkinson, J. A.; Paterson, L. C.; Reid, M.; Tuttle, T.; Andersson, S.; Nilsson, G. N. The Synthesis of Highly Active Iridium(i) Complexes and Their Application in Catalytic Hydrogen Isotope Exchange. Adv. Synth. Catal. 2014, 356 (17), 3551-3562.

(75) Atzrodt, J.; Derdau, V.; Kerr, W. J.; Reid, M. C-H 
Functionalisation for Hydrogen Isotope Exchange. Angew. Chemie - Int. Ed. 2018, 57 (12), 3022-3047.

(76) Lefort, L.; Copéret, C.; Taoufik, M.; Thivolle-Cazat, J.; Basset, J. M. H/D Exchange between $\mathrm{CH}_{4}$ and $\mathrm{CD}_{4}$ catalysed by a Silica Supported Tantalum Hydride, $(\simeq \mathrm{SiO}) 2 \mathrm{Ta}-\mathrm{H}$. Chem. Commun. 2ooo, 36 (8), 663-664.

(77) Vidal, V.; Théolier, A.; Thivolle-Cazat, J.; Basset, J.-M.; Corker, J. Synthesis, Characterization, and Reactivity, in the $\mathrm{C}-\mathrm{H}$ Bond Activation of Cycloalkanes, of a Silica-Supported Tantalum(III) Monohydride Complex: (:SiO)2TaIII-H. J. Am. Chem. Soc. 1996, 118 (19), 4595-4602.

(78) Roux, E. Le; Chabanas, M.; Baudouin, A.; Mallmann, A. de; Copéret, C.; Quadrelli, E. A.; Thivolle-Cazat, J.; Basset, J.-M.; Lukens, W.; Lesage, A.; Emsley, L.; Sunley, G. J. Detailed Structural Investigation of the Grafting of $\left[\mathrm{Ta}(\mathrm{CHtBu})\left(\mathrm{CH}_{2} \mathrm{tBu}\right)_{3}\right]$ and $\left[\mathrm{Cp}^{*} \mathrm{TaMe}_{4}\right]$ on Silica Partially Dehydroxylated at $700{ }^{\circ} \mathrm{C}$ and the Activity of the Grafted Complexes toward Alkane Metathesis. J. Am. Chem. Soc. 2004, 126 (41), 13391-13399.

(79) Prechtl, M. H. G.; Hölscher, M.; Ben-David, Y.; Theyssen, N.; Loschen, R.; Milstein, D.; Leitner, W. H/D Exchange at Aromatic and Heteroaromatic Hydrocarbons Using $\mathrm{D}_{2} \mathrm{O}$ as the Deuterium Source and Ruthenium Dihydrogen Complexes as the Catalyst. Angew. Chemie - Int. Ed. 2007, 46 (13), 2269-2272.

(8o) Yung, C. M.; Skaddan, M. B.; Bergman, R. G. Stoichiometric and Catalytic H/D Incorporation by Cationic Iridium Complexes: A Common Monohydrido-Iridium Intermediate. J. Am. Chem. Soc. 2004, 126 (40), $13033-13043$.

(81) Corriu, R. J. P.; Guari, Y.; Mehdi, A.; Reyé, C.; Thieuleux, C.; Datas, L. Ordered SBA-15 Mesoporous Silica Containing Phosphonic Acid Groups Prepared by a Direct Synthetic Approach. Chem. Commun. 2oo1, 37 (8), 763-764.

(82) Graf, R.; Demco, D. E.; Gottwald, J.; Hafner, S.; Spiess, H. W. Dipolar Couplings and Internuclear Distances by DoubleQuantum Nuclear Magnetic Resonance Spectroscopy of Solids. J. Chem. Phys. 1997, 106 (3), 885-895.

(83) Brown, S. P.; Schnell, I.; Brand, J. D.; Müllen, K.; Spiess, H. W. An Investigation of $\pi-\pi$ Packing in a Columnar Hexabenzocoronene by Fast Magic-Angle Spinning and Double-Quantum $1 \mathrm{H}$ Solid-State NMR Spectroscopy. J. Am. Chem. Soc. 1999, 121 (28), 6712-6718.

(84) Brown, S. P.; Spiess, H. W. Advanced Solid-State NMR Methods for the Elucidation of Structure and Dynamics of Molecular, Macromolecular, and Supramolecular Systems. Chem. Rev. 2001, 101 (12), 4125-4155.

(85) Hohwy, M.; Jakobsen, H. J.; Edén, M.; Levitt, M. H.; Nielsen, N. C. Broadband Dipolar Recoupling in the Nuclear Magnetic Resonance of Rotating Solids: A Compensated $\mathrm{C}_{7}$ Pulse Sequence. J. Chem. Phys. 1998, 108 (7), 2686-2694.

(86) Marion, D.; Ikura, M.; Tschudin, R.; Bax, A. Rapid Recording of $2 \mathrm{D}$ NMR Spectra without Phase Cycling. Application to the Study of Hydrogen Exchange in Proteins. J. Magn. Reson. 1989, 85 (2), 393-399.

(87) Edén, M.; Levitt, M. H. Excitation of Carbon-13 Triple Quantum Coherence in Magic-Angle-Spinning NMR. Chem. Phys. Lett. 1998, 293 (3-4), 173-179.

(88) Carravetta, M.; Schmedt auf der Günne, J.; Levitt, M. H. Enhanced Triple-Quantum Excitation in ${ }_{13} \mathrm{C}$ Magic-Angle Spinning NMR. J. Magn. Reson. 2003, 162 (2), 443-453.

(89) Schnell, I.; Lupulescu, A.; Hafner, S.; Demco, D. E.; Spiess, H. W. Resolution Enhancement in Multiple-Quantum MAS NMR Spectroscopy. J. Magn. Reson. 1998, 133 (1), 61-69.

(90) Schnell, I.; Spiess, W. H. High-Resolution ${ }_{1} \mathrm{H}$ NMR Spectroscopy in the Solid State: Very Fast Sample Rotation and Multiple-Quantum Coherences. J. Magn. Reson. 2oo1, 151 (2), 153-227.

(91) Shantz, D. F.; Schmedt Auf Der Günne, J.; Koller, H.; Lobo, R. F. Multiple-Quantum 1 H MAS NMR Studies of Defect Sites in as-Made All- Silica ZSM-12 Zeolite. J. Am. Chem. Soc. 2000, 122 (28), 6659-6663.
(92) Adamo, C.; Barone, V. Toward Reliable Density Functional Methods without Adjustable Parameters: The PBEo Model. J. Chem. Phys. 1999, 110 (13), 6158-6170.

(93) Weigend, F.; Ahlrichs, R. Balanced Basis Sets of Split Valence, Triple Zeta Valence and Quadruple Zeta Valence Quality for H to Rn: Design and Assessment of Accuracy. Phys. Chem. Chem. Phys. 2005, 7 (18), 3297-3305.

(94) Frisch, M. J.; Trucks, G. W.; Schlegel, H. B.; Scuseria, G. E.; Robb, M. A.; Cheeseman, J. R.; Scalmani, G.; Barone, V.; Mennucci, B.; Petersson, G. A.; Nakatsuji, H.; Caricato, M.; Li, X.; Hratchian, H. P.; Izmaylov, A. F.; Bloino, J.; Zheng, G.; Sonnenberg, J. L.; Had, M.; et al. Gaussian o9. Gaussian Inc.: Wallingford CT 2013.

(95) Andrae, D.; Häußermann, U.; Dolg, M.; Stoll, H.; Preuß, H. Energy-Adjusted Ab Initio Pseudopotentials for the Second and Third Row Transition Elements. Theor. Chim. Acta 1990 , 77 (2), 123-141.

(96) Marenich, A. V.; Cramer, C. J.; Truhlar, D. G. Universal Solvation Model Based on Solute Electron Density and on a Continuum Model of the Solvent Defined by the Bulk Dielectric Constant and Atomic Surface Tensions. J. Phys. Chem. B 2009, 113 (18), 6378-6396.

(97) Roos, B. O.; Taylor, P. R.; Sigbahn, P. E. M. A Complete Active Space SCF Method (CASSCF) Using a Density Matrix Formulated Super-CI Approach. Chem. Phys. 1980, 48 (2), 157-173.

(98) Aquilante, F.; Autschbach, J.; Carlson, R. K.; Chibotaru, L. F.; Delcey, M. G.; De Vico, L.; Fdez. Galván, I.; Ferré, N.; Frutos, L. M.; Gagliardi, L.; Garavelli, M.; Giussani, A.; Hoyer, C. E.; Li Manni, G.; Lischka, H.; Ma, D.; Malmqvist, P. Å.; Müller, T.; Nenov, A.; et al. Molcas 8: New Capabilities for Multiconfigurational Quantum Chemical Calculations across the Periodic Table. J. Comput. Chem. 2016, 37 (5), 506541.

(99) Roos, B. O.; Lindh, R.; Malmqvist, P. Å.; Veryazov, V.; Widmark, P. O. New Relativistic ANO Basis Sets for Transition Metal Atoms. J. Phys. Chem. A 2005, 109 (29), $6575-6579$.

(100) Roos, B. O.; Lindh, R.; Malmqvist, P. Å.; Veryazov, V.; Widmark, P. O. Main Group Atoms and Dimers Studied with a New Relativistic ANO Basis Set. J. Phys. Chem. A 2004, 108 (15), 2851-2858.

(101) Hess, B. A. Relativistic Electronic-Structure Calculations Employing a Two-Component No-Pair Formalism with External-Field Projection Operators. Phys. Rev. A 1986, 33 (6), 3742-3748.

(102) Aquilante, F.; Malmqvist, P. Å.; Pedersen, T. B.; Ghosh, A.; Roos, B. O. Cholesky Decomposition-Based Multiconfiguration Second-Order Perturbation Theory (CDCASPT2): Application to the Spin-State Energetics of Co III(Diiminato)(NPh). J. Chem. Theory Comput. 2008, 4 (5), 694-702.

(103) Aquilante, F.; Pedersen, T. B.; Lindh, R.; Roos, B. O.; Sánchez De Merás, A.; Koch, H. Accurate Ab Initio Density Fitting for Multiconfigurational Self-Consistent Field Methods. J. Chem. Phys. 2008, 129 (2), 024113.

(104) Aquilante, F.; Gagliardi, L.; Pedersen, T. B.; Lindh, R. Atomic Cholesky Decompositions: A Route to Unbiased Auxiliary Basis Sets for Density Fitting Approximation with Tunable Accuracy and Efficiency. J. Chem. Phys. 2009, 130 (15), 154107.

(105) Aquilante, F.; Pedersen, T. B.; Lindh, R. Low-Cost Evaluation of the Exchange Fock Matrix from Cholesky and Density Fitting Representations of the Electron Repulsion Integrals. J. Chem. Phys. 2007, 126 (19), 194106.

(106) Kresse, G.; Furthmüller, J. Efficient Iterative Schemes for Ab Initio Total-Energy Calculations Using a Plane-Wave Basis Set. Phys. Rev. B - Condens. Matter Mater. Phys. 1996, 54 (16), 11169-11186.

(107) Kresse, G.; Furthmüller, J. Efficiency of Ab-Initio Total Energy Calculations for Metals and Semiconductors Using a Plane-Wave Basis Set. Comput. Mater. Sci. 1996, 6 (1), 15-50. 
(108) Perdew, J. P.; Burke, K.; Ernzerhof, M. Generalized Gradient Approximation Made Simple. Phys. Rev. Lett. 1996, 77 (18), 3865-3868.

(109) Grimme, S.; Antony, J.; Ehrlich, S.; Krieg, H. A Consistent and Accurate $\mathrm{Ab}$ Initio Parametrization of Density Functional Dispersion Correction (DFT-D) for the 94 Elements H-Pu. J. Chem. Phys. 2010, 132 (15), 154104.

(110) Blöchl, P. E. Projector Augmented-Wave Method. Phys. Rev. $B$ 1994, 50 (24), 17953-17979.

(111) Joubert, D. From Ultrasoft Pseudopotentials to the Projector Augmented-Wave Method. Phys. Rev. B - Condens. Matter Mater. Phys. 1999, 59 (3), 1758-1775.

(112) Rozanska, X.; Delbecq, F.; Sautet, P. Reconstruction and Stability of $\beta$-Cristobalite o01, 101, and 111 Surfaces during Dehydroxylation. Phys. Chem. Chem. Phys. 2010, 12 (45), 14930-14940. 

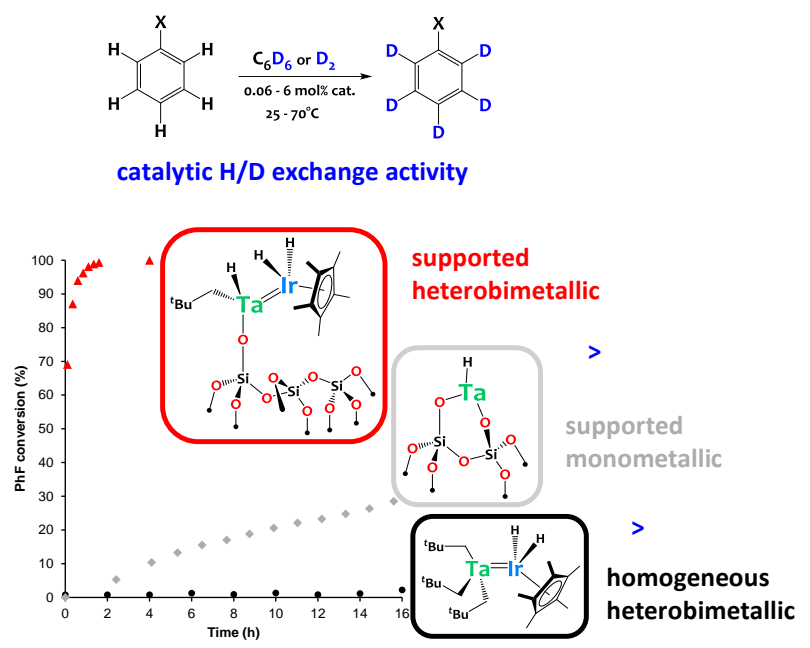